\title{
Australian tidal currents - assessment of a barotropic model with an unstructured grid.
}

\author{
David A. Griffin ${ }^{1}$, Mike Herzfeld ${ }^{1}$, Mark Hemer ${ }^{1}$
}

${ }^{1}$ Oceans and Atmosphere, CSIRO, Hobart, TAS 7000, Australia

\section{Correspondence to: David Griffin (David.Griffin@csiro.au)}

\begin{abstract}
While the variations of tidal range are large and fairly well known across Australia (less than $1 \mathrm{~m}$ near Perth but more than $14 \mathrm{~m}$ in King Sound), the properties of the tidal currents are not. We describe a new regional model of Australian tides and assess it against a validation dataset comprising tidal height and velocity constituents at 615 tide gauge sites and 95 current meter sites. The model is a barotropic implementation of COMPAS, an unstructured-grid primitive-equation model that is forced at the open boundaries by TPXO9v1. The Mean Absolute value of the Error (MAE) of the modelled M2 height amplitude is $9.3 \mathrm{~cm}$, or $13 \%$ of the $73 \mathrm{~cm}$ mean observed amplitude. The MAE of phase $\left(11^{\circ}\right)$, however, is significant, so the M2 Mean Magnitude of Vector Error (MMVE, $20 \mathrm{~cm}$ ) is significantly greater. Results for 5 other major constituents are similar. We conclude that while the model has skill at height in all regions, there is definitely room for improvement (especially at some specific locations) before harmonic predictions based on observations are rendered obsolete. For the M2 major-axis velocity amplitude, the MAE across the 95 current meter sites, where the observed amplitude ranges from $0.1 \mathrm{~cm} \mathrm{~s}^{-1}$ to 144 $\mathrm{cm} \mathrm{s}^{-1}$, is $6.5 \mathrm{~cm} \mathrm{~s}^{-1}$, or $20 \%$ of the $31.7 \mathrm{~cm} \mathrm{~s}^{-1}$ observed mean. This nationwide average result is not much greater than the equivalent for height, but it conceals a larger regional variation. Relative errors on the narrow shelves of NSW and Western Australia exceed $100 \%$, but tidal currents are weak and negligible there compared to non-tidal currents. We show that the model has predictive value for much of the $79 \%$ of Australia's shelf seas where tides are a major component of the total velocity variability. In descending order this includes the Bass Strait, Kimberley to Arnhem Land and Southern Great Barrier Reef regions. There is limited evidence the model is also valuable for currents in other regions across northern Australia. We plan to commence publishing 'unofficial' tidal current predictions for chosen regions in the near future, based on both the limited number of observations, and the COMPAS model.
\end{abstract}

\section{Introduction}

25 Tidal currents are a major component of the velocity variability for most of the Australian continental shelf, yet tidal current predictions are only listed in the Australian National Tide Tables for 7 sites, 5 of which are in Torres Strait. As part of a project to map Australia's tidal energy resource, and as a step towards an operational, model-based tidal current forecasting ability, we have compiled a tidal currents harmonic constituents validation dataset at 95 sites based on observations acquired by a number of agencies. This is a significant number of sites, but it is still small compared to the 683 sites for which the Bureau of

30 Meteorology Tidal Unit has estimates of tidal height harmonic constituents. We use these validation datasets for currents and 
heights to assess the errors of a newly configured barotropic implementation of an unstructured-grid tidal model for the Australian continental shelf. This tells us how well the tidal component of the total variability can be predicted. Taking nontidal currents into account as well, we identify the regions of Australia where model-based tidal current predictions are not only accurate, but also a large part of the total variability.

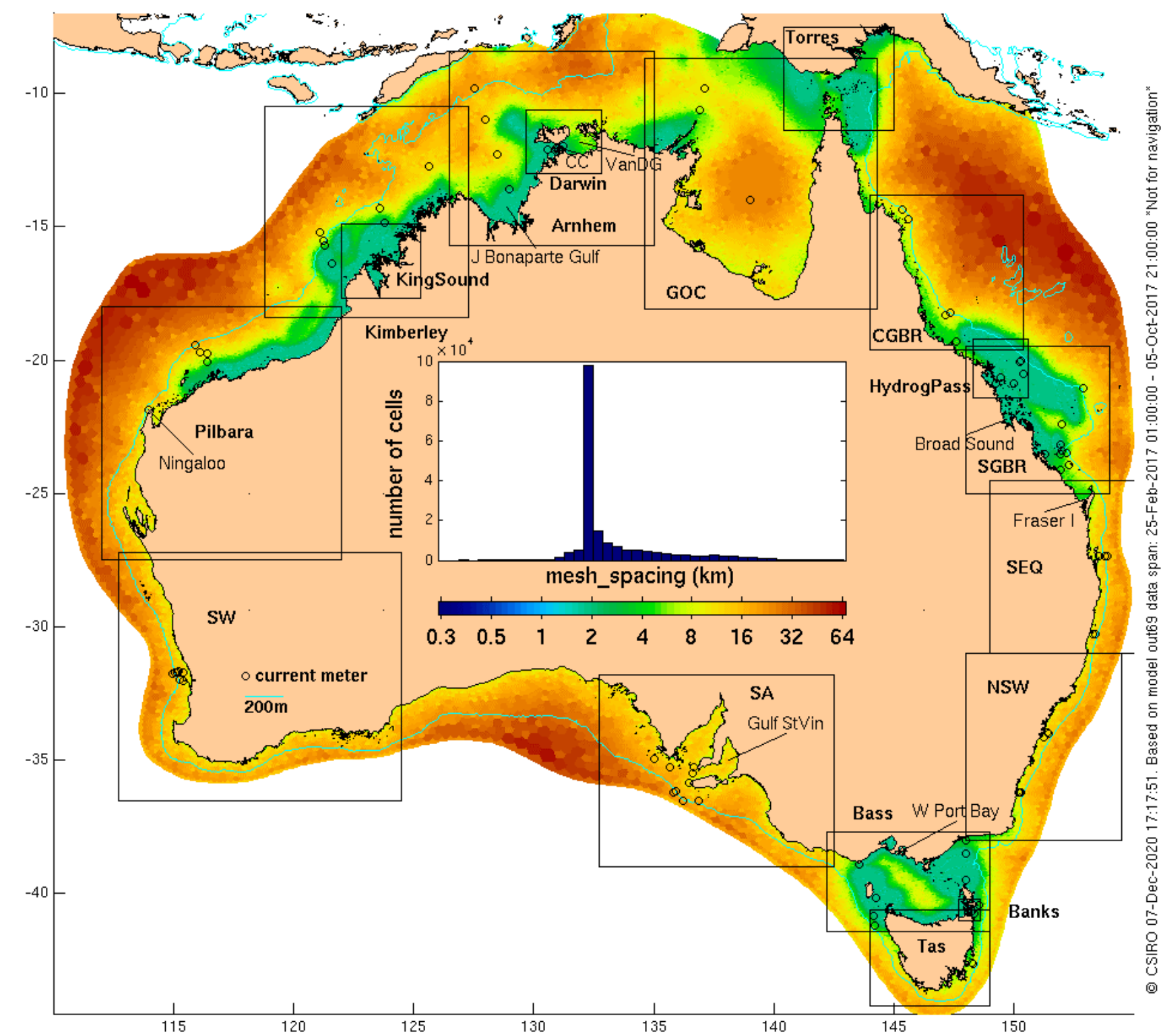

Figure 1 Model mesh spacing (km, log scale). Abbreviated names are: CC=Clarence Channel, VanDG=Van Diemen Gulf, GOC=Gulf of Carpentaria, CGBR=Central Great Barrier Reef, SGBR=Southern GBR, SEQ=Southeast Queensland, NSW=New South Wales, Bass=Bass Strait, Tas=Tasmania, Banks=Banks Strait, SA=South Australia, SW=South West. 


\section{$40 \quad 2$ Model configuration}

We generated time-series of tidal predictions surrounding Australia using the unstructured model COMPAS (Coastal Ocean Model Prediction Across Scales) (Herzfeld et al., 2020). This model was chosen over structured model counterparts due to its capacity for superior resolution placement and transition, allowing high resolution to be exactly prescribed in areas of interest, and low resolution elsewhere. This significantly reduces the number of cells required to model such a large domain, resulting

45 in an acceptable computational cost. COMPAS is a coastal ocean model designed to be used at scales ranging from estuaries to regional ocean domains. It is a three-dimensional (3D) finite volume hydrodynamic model based on the 3D equations of momentum, continuity and conservation of heat and salt, employing the hydrostatic and Boussinesq approximations. The equations of motion are discretised on arbitrary polygonal meshes according to the TRiSK numerics (Thuburn et al., 2009; Ringler et al., 2010), which is a generalisation of the standard Arakawa C-grid scheme to unstructured meshes. The horizontal

50 terms in the governing equations (momentum advection, horizontal mixing and Coriolis) are discretised using the TRiSK numerics, whereas the pressure gradient and vertical mixing are discretised using the finite difference approach outlined by Herzfeld (2006). The horizontal mesh must be an orthogonal, centroidal and well-centred "primal-dual" tessellation, typically consisting of collections of Voronoi cells and their dual Delaunay triangles. The 3D model may operate using "z" or s vertical coordinates; however, in the present application a depth-averaged configuration is used. The bottom topography is represented

55 using partial cells. COMPAS has a nonlinear free surface and uses mode splitting to separate the two-dimensional (2D) mode from the 3D mode. The model uses explicit time-stepping throughout, except for the vertical diffusion scheme which is implicit.

COMPAS uses the unstructured meshing library JIGSAW (Engwirda, 2017) to generate the underlying unstructured mesh.

60 JIGSAW produces high quality meshes that support the requirements of the TRiSK numerics. The mesh of the model discussed here was generated using a dual weighting function dependent on bottom depth and tidal current speed, such that those regions with shallow water and high tidal velocities receive high resolution and vice versa. An initial configuration with resolution depending on tidal height amplitude gave poor results because some straits with strong flows but only moderate height amplitude received only moderate resolution. The mesh has 183,810 2D cells with an indicative cell size ranging from $332 \mathrm{~m}$

65 to $63 \mathrm{~km}$ (Fig. 1). Eighty per cent of cells have sizes between $1900 \mathrm{~m}$ and $7100 \mathrm{~m}$. The mean length of edges in the mesh is $3680 \mathrm{~m}$. Note that a regular structured grid covering the same spatial domain at the same mean resolution would require $\sim 1.5$ million 2D cells.

The model topography (Fig. 2) uses bathymetry from the Geosciences Australia (2002) database, with regions outside its extent filled using the global database dbdb2 (Naval Research Laboratory Digital Bathymetry Data Base 70 https://www7320.nrlssc.navy.mil/DBDB2_WWW/). This was supplemented with high resolution datasets in the Great Barrier 
Reef (Beaman, 2010) and northern Australia (https://ecat.ga.gov.au/geonetwork/srv/eng/catalog.search\#/metadata/121620). Onsite depth measurements at the locations (Fig. 2) of the tidal currents validation data discussed below were not used for estimating the model topography. The minimum depth (at zero tide) in the model is $4 \mathrm{~m}$ for most of the grid, but $8 \mathrm{~m}$ in the NW, NE and in Gulf St Vincent. Depth was median filtered to remove sharp gradients. A deeper channel of $12 \mathrm{~m}$ was also included in King Sound (in the NW). These bathymetric changes had significant effect on the tidal response, and it is anticipated that further model improvement will require targeted bathymetry modification at the local scale.

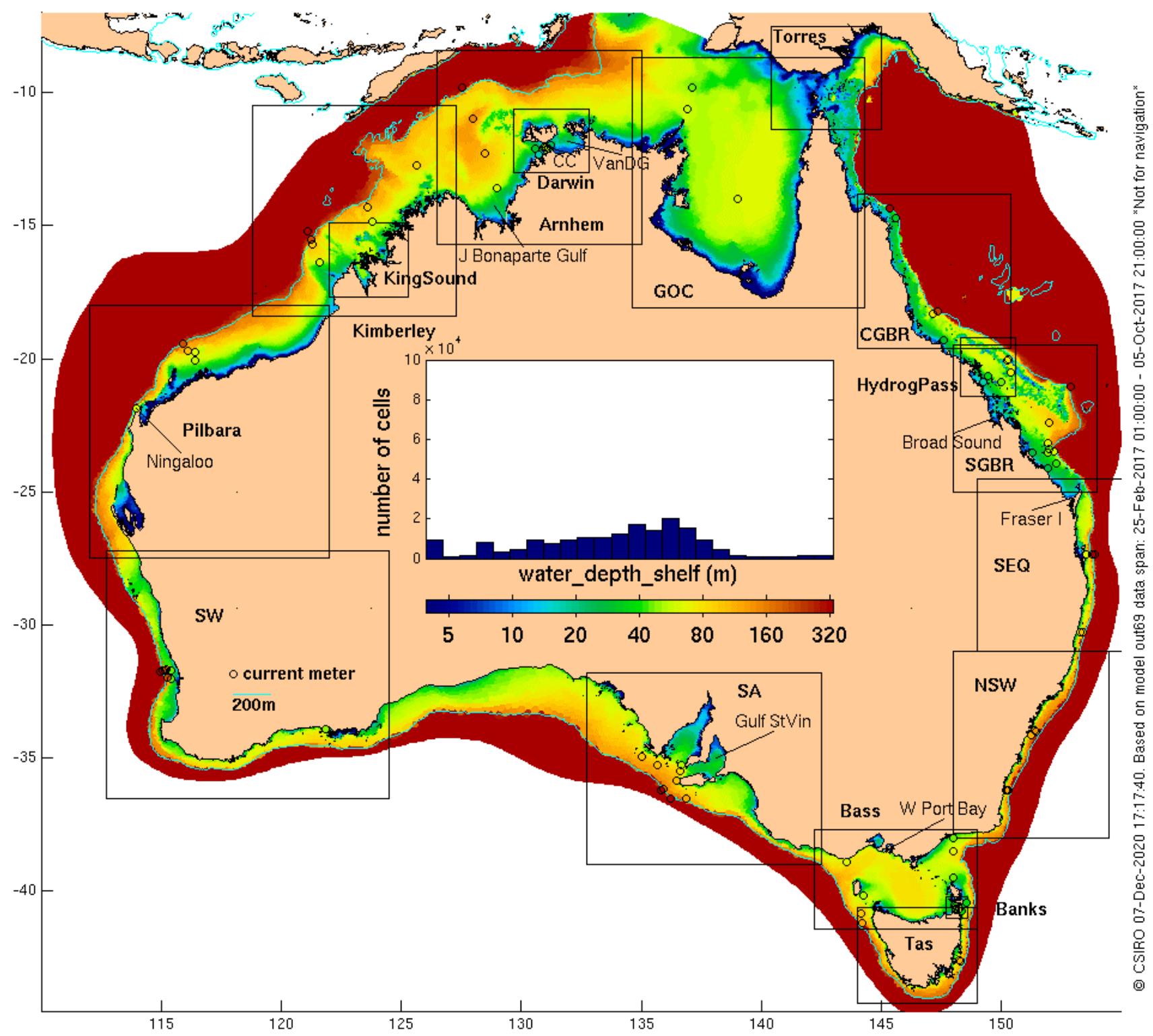

Figure 2 Model depth (m, log scale, spanning just a restricted range). Otherwise like Fig. 1. 
The tide is introduced through eight tidal constituents (M2 S2 N2 K2 K1 O1 P1 Q1) from the TPXO9v1 1/6 ${ }^{\circ}$ global model (Egbert and Erofeeva, 2002; http://volkov.oce.orst.edu/tides/otps.html) and applied at the open boundary using the condition described by Herzfeld et al. (2020). The Herzfeld et al. (2020) scheme includes a normal and tangential velocity Dirichlet condition with provision for a local flux adjustment on normal velocity to maintain domain-wide volume continuity. Thus, the surface height is not directly constrained at the boundary but is instead computed via volume flux divergence as it is in the model interior. For the present application, we found that flux adjustments to constrain the sea surface height were not required; prescribing the transports at the boundary was sufficient to achieve the target height. This situation is quite unusual. One necessary step to achieve this was to use the TPXO components of transport on their native (Arakawa C) grid and use the depths in COMPAS to convert the transports to depth-averaged, cell-edge normal velocity, thus accounting for bathymetry differences between our model and the TPXO model. The model was run in 2D mode only, using a time-step of $1 \mathrm{~s}$, achieving a runtime of $\sim 5: 1$ on twelve processors. A spatially constant bottom drag coefficient of 0.003 was used to compute bottom stress. Tidal potential forcing is optionally applied in the model but we found that it made very little difference compared with other parameters such as friction, so we have omitted it for the configuration described here.

For many test runs of the model, it was started from rest and run for either 7 or 30 days from 24 Feb 2017 including a 1 -day ramp period. Results were compared with harmonically synthesised time series at all sites for which tidal constituents are available (see below) using T-Tide (v1.3b, Pawlowicz et al., 2002) and then parameters were manually adjusted, or model code de-bugged or improved, in search of closer agreement with the observations. Apart from this 'tuning', no data assimilation was used with these model runs.

For the model configuration described here, it was run for 222 days from 24 Feb to 5 Oct 2017, and then tidally analysed so that 1) its performance can be described for individual constituents, and 2) predictions can be made for any time or place within the domain without having to run the model. The COMPAS model code, the output time series and tidal constituents at all points of the mesh are freely available, as described in Sections 9 and 10.

\section{Current meter observations}

Acoustic Doppler current profilers (ADCPs) of various types have been deployed as part of Australia's Integrated Marine Observing System (IMOS) at 55 sites over the continental shelf around Australia, some for several years, since 2007. The ADCPs are almost all moored within a few metres of the sea bed, and sense the water velocity over the lower 80-85\% of the

105 water column. We have taken the depth-average of these observations, concatenated all records from individual instrument deployments at the same nominal position, and determined the tidal constituents using the UTide software of Codiga (2011). Apart from the deployments off the NW of the continent, these sites tend to be at locations where tidal currents are not particularly strong. As a means of quantifying the relative magnitude of tidal and sub-tidal depth-average velocity, we determined the principal axis of the subtidal variability (using singular value decomposition) and computed the root mean

110 square (RMS) of the major and minor axis components. Details of the IMOS ADCP deployments are at 
http://oceancurrent.imos.org.au/timeseries/ along with regional graphics comparing the tidal and sub-tidal ellipse parameters (as well as the mean velocity for each deployment).

Penesis et al. (2020) give details of ADCP deployments that deliberately sought to observe tidal currents for two of Australia's most prospective tidal energy development regions. These include seven locations in the Clarence Channel near Darwin and

115 seven locations in Banks Strait at the NE tip of Tasmania. We determined tidal velocity constituents, the mean and sub-tidal ellipse parameters from these data as above.

We have included data from 10 of the sites where Middleton et al. (1984) and Griffin et al. (1987) deployed current meters on the Southern Great Barrier Reef (SGBR, see Fig. 2) in order to study both the anomalous tides and the sub-tidal variability. These observations were made by single, mechanical RCM4 Aanderaa current meters with several drawbacks compared to

120 ADCPs. Due to limited storage capacity, the flow direction was only sampled instantaneously once an hour, so short-period changes of direction were not averaged. To minimise noise due to waves, the instruments were moored fairly low in the water column (typically $7 \mathrm{~m}$ off the seabed), thereby probably underestimating the depth-average velocity. Some had to be deployed close to islands, with the result that they recorded effects (such as asymmetric ebb and flood directions) that the model is unlikely to be able to reproduce at specific locations due to its imperfect representation of topography. Nevertheless, we have included these records in our validation dataset, processed as above, despite the quality questions because 1) the tides in this region are important for navigation (e.g. through Hydrographers Passage), and 2) in the hope that future models with finer meshes and better topography may be able to better distinguish observation error from model error.

Lastly, we also extracted 13 current meter records from the CSIRO archives (https://www.cmar.csiro.au/data/trawler/), choosing sites in Bass Strait, the NW shelf and the Gulf of Carpentaria where tidal currents are significant. These were mostly point measurements, either by acoustic or mechanical (Aanderaa) current meters. Where two instruments were deployed on a mooring, we simply averaged the data for the period when both were operating.

In support of this paper and future studies of the tides of Australia, we have published this validation data set as a netCDF file containing up to 13 tidal constituents, and the subtidal statistics, for each of the 95 locations discussed above (see Section 10).

\section{Tide gauges}

135 The National Operations Centre (NOC) Tidal Unit of the Bureau of Meteorology (http://www.bom.gov.au/oceanography/projects/ntc/ntc.shtml) kindly provided tidal height constituents for 683 sites, of which 626 are within the COMPAS domain. To this we have added nine sites from the UNSW SGBR dataset bringing the total to 635 before applying quality control. 
https://doi.org/10.5194/os-2020-107

Preprint. Discussion started: 11 December 2020

\section{Model-data comparison method}

140 All model-data comparisons presented in this paper are based on the six major tidal constituents (M2, S2, N2, K1, O1 and P1) determined from the model and observational time-series (rather than the time series approach used during model tuning) for all the usual reasons. The length of the analysed model run (222days) is long enough to resolve P1 from K1 but we do not discuss results for these lesser constituents (important as they are for predictions) in detail because the results for M2 are broadly representative of all constituents. Availability of the full set of model-data comparisons for 6 constituents, 18 regions and 5 variables is covered in Section 10.

\subsection{Tide gauges}

When comparing the model with tide gauges, we select the closest model grid point if one exists within $11 \mathrm{~km}$. We calculate the model error (model minus observation) for amplitude and phase individually as well as the vector error (taking both phase and amplitude into account) for each tidal constituent. Summing over a number of sites within a certain geographic region, we then compute the Mean of the Absolute value of the amplitude Error (MAE), the Mean Magnitude of Vector Error (MMVE), the mean of the amplitude error and the mean of the observed amplitude (for expressing the MAE or MMVE as a relative error or RE). We use MAE and MMVE in preference to root-mean-squared errors because the MAE and MMVE are less affected by outliers. Outliers are a significant issue, as we will discuss below with reference to Table 1, which lists the sites we have chosen to exclude from the tidal heights dataset. We combine analyses for the six constituents by computing the Root Sum of Squared (RSS) MAEs and MMVEs. In order to estimate the total regional-mean tidal relative error, we also compute the RSS of the area-mean observed amplitudes. These statistics are computed for a number of regions (bounding boxes are shown in Fig. 1) around Australia as well as for the entire country and listed in Table 2. We have not attempted to account for the uneven distribution of the data points around Australia, other than to compute regional means as well as the nationwide means. Nor have we attempted to estimate errors of the observational tidal constituents based on factors such as record length or instrument type.

\subsection{Current meters}

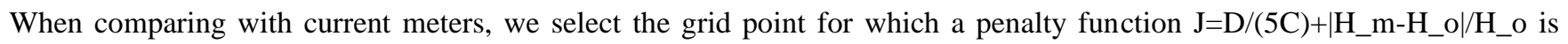
minimised, where D are the distances to the model grid point, $\mathrm{C}$ are the sizes of the cells, H_m are the model depths and H_o is the onsite depth at the observation point. This is an attempt to mitigate the effect of the model's imperfect topography, by

165 finding the nearest depth-matching (if possible) model counterpart of the observation. We then proceed as for tide gauges, but with the amplitude and phase of the major axis velocity taking the place of height. Errors of the major axis inclination and minor axis amplitude are shown graphically and are listed in Table 3 but are not otherwise included. Three sorts of site-specific relative error are listed in Table 3:1) the M2 major axis velocity amplitude error relative to the observed amplitude reM2= $\left.\left(\left|m a j_{m}\right|-\left|m a j_{o}\right|\right) /\left|m a j_{o}\right|, 2\right)$ the M2 major axis velocity vector error relative to the observed amplitude $r e \overline{M 2}=$ 
$170\left|m a j_{m}-m a j_{o}\right| /\left|m a j_{o}\right|$, and 3) reLF, which has the observed sub-tidal ('low frequency') RMS major axis velocity sub_o included in both numerator and denominator. The first two measures characterise the model's ability to do what it is designed for, which is just to simulate tides. The first of these is for users who need to know tidal range but not at any particular time. The second is for applications where timing is also important. The third acknowledges that tides are not the dominant component of velocity variability everywhere. Using a tidal model alone (i.e. without a model of other processes) to predict

175 the total current (characterised by maj_o+sub_o) will result in an error determined by $s u b \_o$ if the tidal error is zero. Where tidal and sub-tidal variability are equal, the upper limit of reLF is $50 \%$.

Table 3 lists sites by ascending reLF, and includes averages of the sites with lowest, middle and greatest reLF, for most columns. For the ' $m-o$ ' column the average is mathematically an MAE, but with a non-geographic sample of sites. Table 4 is like Table 2, with major axis velocity amplitude and phase taking the place of height amplitude and phase, for the same six constituents.

\section{Results}

\subsection{Tidal height}

Since we have no reliable, objective (model independent) way of knowing which tide gauge observations (or more precisely, the analysed tidal constituents) are more accurate than others, we have cautiously employed a largely model-based quality control procedure. This procedure excludes sites if:

- The absolute value of M2 error exceeds $20 \mathrm{~cm}$ and an observed M2 amplitude within $10 \mathrm{~km}$ is less by more than $20 \mathrm{~cm}$ (excludes four sites)

- $\quad$ The observed amplitude is less than $4 \mathrm{~cm}$ (two sites)

- The observed amplitude exceeds $10 \mathrm{~cm}$ and is less than half, or more than twice the model amplitude (14 sites)

- The observed and modelled phase differ by more than $90^{\circ}$ (six sites).

Table 1: Blacklisted tide gauges. Tests are on the nearest neighbour difference $(\mathrm{cm})$, the observed M2 amplitude and the model M2 amplitude and phase relative to the observed values.

\begin{tabular}{|l|l|l|l|l|l|l|l|}
\hline Site\# & Site & Latitude & Longitude & nndiff & \multicolumn{2}{l|}{ Observed Model } & Phase diff \\
\hline 67 & Kai-Maituine Reef - Northeast & $10.23 \mathrm{~S}$ & $143.15 \mathrm{E}$ & 0 & 69 & 60 & 100 \\
105 & Sharp Point & $10.97 \mathrm{~S}$ & $142.72 \mathrm{E}$ & -49 & 23 & 91 & -32 \\
125 & Harvey Island & $11.97 \mathrm{~S}$ & $143.27 \mathrm{E}$ & -44 & 19 & 74 & 6 \\
152 & Endeavour River North & $15.43 \mathrm{~S}$ & $145.2 \mathrm{E}$ & -22 & 31 & 57 & -3 \\
187 & Rib Reef & $18.47 \mathrm{~S}$ & $146.87 \mathrm{E}$ & 0 & 22 & 68 & -3 \\
333 & South Channel & $38.3 \mathrm{~S}$ & $144.71 \mathrm{E}$ & -5 & 21 & 9 & 31 \\
378 & Maatsuyker Island & $43.67 \mathrm{~S}$ & $146.32 \mathrm{E}$ & 0 & 23 & 9 & 25 \\
\hline
\end{tabular}




\begin{tabular}{|c|c|c|c|c|c|c|c|}
\hline 457 & Nornalup Inlet & $35 \mathrm{~S}$ & $116.73 \mathrm{E}$ & 0 & 2 & 6 & -48 \\
\hline 465 & Mandurah & $32.53 \mathrm{~S}$ & $115.72 \mathrm{E}$ & 0 & 3 & 5 & -13 \\
\hline 490 & Monkey Mia & $25.8 \mathrm{~S}$ & $113.72 \mathrm{E}$ & 0 & 38 & 9 & 28 \\
\hline 577 & Bonaparte Gulf & $12.83 \mathrm{~S}$ & $128.47 \mathrm{E}$ & 0 & 14 & 82 & -132 \\
\hline 586 & Catfish Island & $14 \mathrm{~S}$ & $129.48 \mathrm{E}$ & 86 & 268 & 173 & -42 \\
\hline 631 & Peacock Island & $11.02 \mathrm{~S}$ & $132.45 \mathrm{E}$ & 0 & 19 & 64 & 21 \\
\hline 659 & Mallison Island & $12.18 \mathrm{~S}$ & $136.1 \mathrm{E}$ & 0 & 173 & 12 & 94 \\
\hline 668 & Centre Island & $15.75 \mathrm{~S}$ & $136.81 \mathrm{E}$ & 0 & 40 & 15 & 47 \\
\hline 669 & Mornington Island & $16.67 \mathrm{~S}$ & $139.17 \mathrm{E}$ & 0 & 14 & 7 & 44 \\
\hline 670 & West Wellesley Islands & $16.8 \mathrm{~S}$ & $138.96 \mathrm{E}$ & 0 & 16 & 8 & 41 \\
\hline 672 & Albert River Mouth & $17.55 \mathrm{~S}$ & $139.76 \mathrm{E}$ & 0 & 20 & 10 & 125 \\
\hline 674 & Sweers Island & $17.11 \mathrm{~S}$ & $139.59 \mathrm{E}$ & 0 & 15 & 5 & 115 \\
\hline \multirow[t]{3}{*}{675} & Karumba & $17.49 \mathrm{~S}$ & $140.83 \mathrm{E}$ & 0 & 17 & 14 & 97 \\
\hline & Failure criterion & & & $>20 \mathrm{~cm}$ & $<4 \mathrm{~cm}$ & $0 * 0.5,0 * 2$ & $>90^{\circ}$ \\
\hline & Number of failures & & & 4 & 2 & 14 & 6 \\
\hline
\end{tabular}

With the 20 sites listed in Table 1 excluded, the M2 MAE across 615 sites is $9.3 \mathrm{~cm}$, or $13 \%$ of the mean observed amplitude, which is $72.5 \mathrm{~cm}$. The resulting scatter plot (Fig. 3, note the log-log axes) of model vs observed height amplitude still has points that could be considered outliers; at $5 \%$ of sites the negative errors are $\sim 3$ to 10 times the MAE. But we have not excluded these along with the other 20 , for lack of clear evidence that they are due to observation error rather than model error.

200 The bias is relatively small but not insignificant $(-2.3 \mathrm{~cm}$, see Table 2$)$. It is negative because most of the biggest errors are cases of the observation exceeding the modelled amplitude. The region with the biggest negative M2 bias (-11 cm) is clearly (see Table 2) the Southern Great Barrier Reef, where the model underpredicts the large tides within about $100 \mathrm{~km}$ of the head of Broad Sound

The region with the biggest M2 amplitude MAE is the one we abbreviate here as 'Arnhem' (rather than Joseph Bonaparte Gulf and Arnhem Land) but across this region there is a mix of under and over-prediction. The modelled M2 height amplitude is too small in Van Diemen Gulf and the head of Joseph Bonaparte Gulf but too great at many of the offshore sites where the observed amplitude is small.

There are large M2 phase errors (Fig. 4) at many sites. While some are possibly due to observation error, the predominance of positive phase errors, especially in regions of strong tides, points to a problem in the model. The region with the biggest M2 phase MAE is the Kimberley $\left(20^{\circ}\right)$ (Table 2), nearly twice the all-site average of $11.5^{\circ}$. The significant phase errors are why the Australia-wide M2 MMVE $(20 \mathrm{~cm})$ is so much greater than the M2 MAE $(9.3 \mathrm{~cm})$.

The next most energetic constituent after M2 $(72.5 \mathrm{~cm}$ averaged across all sites) is $\mathrm{S} 2(35.8 \mathrm{~cm}) . \mathrm{S} 2 \mathrm{has}$ the next-greatest MMVE (12.9 cm, because of large phase errors in the Kimberley), then K1 (with $29.6 \mathrm{~cm}$ observed amplitude) has a MMVE of $7.7 \mathrm{~cm}$.

215 Summing over six constituents, and taking both phase and amplitude errors into account, the RSS MMVE across all sites is $26.1 \mathrm{~cm}$, or $29.1 \%$ of the mean observed amplitude. The three regions with the lowest relative error $(11.9,14.4$ and $16.8 \%)$ 
are Central Great Barrier Reef, New South Wales and the South West, while the three regions with the highest $(38.9,36.4$ and 35.6\%) are the wide shallow seas in the tropics: Torres Strait, Joseph Bonaparte Gulf and Arnhem Land and Gulf of Carpentaria. Thus, the greatest regional-average relative errors of modelled height are about twice the size of the least. Both are small enough to conclude that the model has skill, but large enough to conclude that there is still room for improvement.

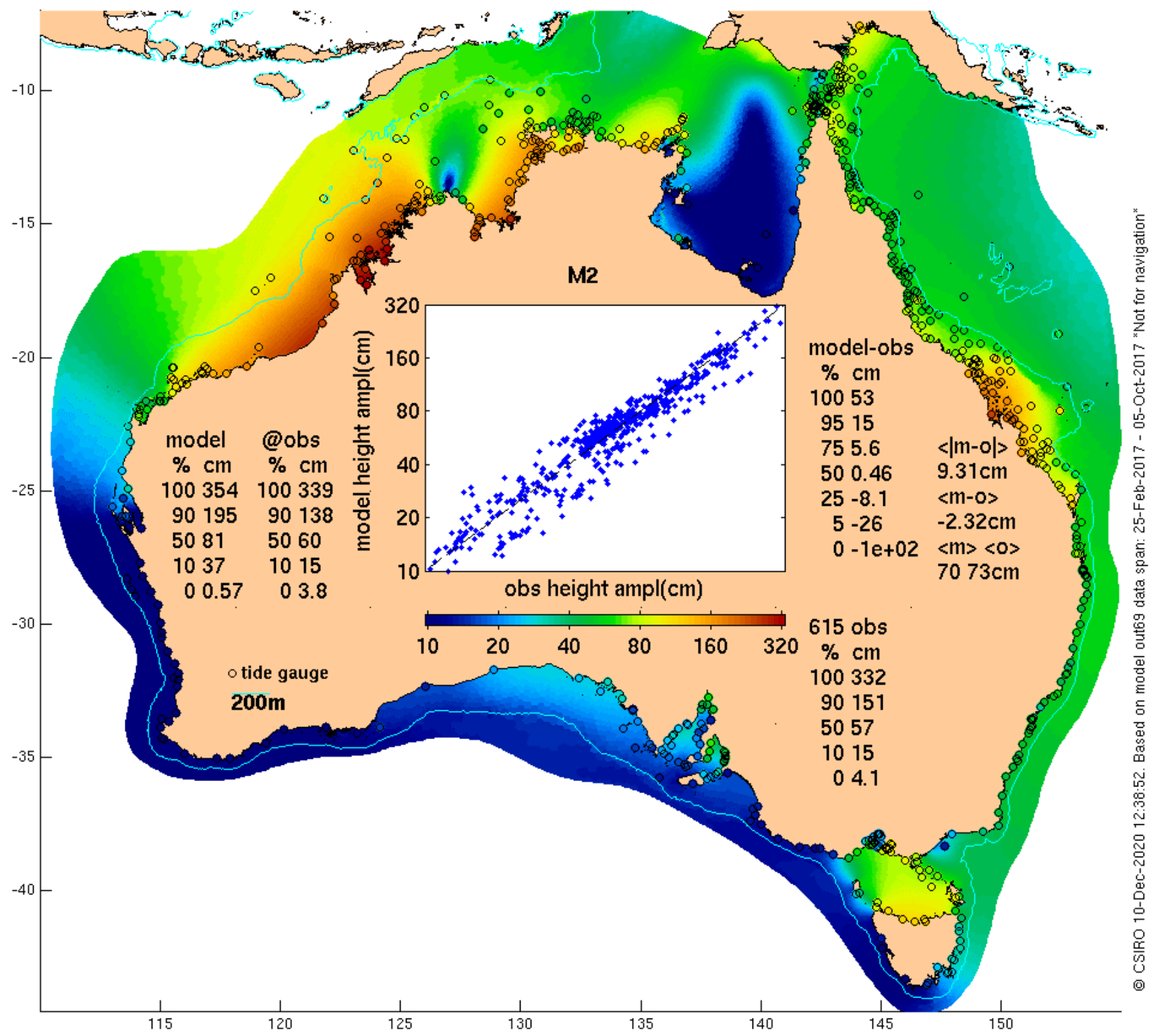

Figure $3 \mathrm{M} 2$ height amplitude as a colour-fill map (the model) and points (observations), and inset as a quantity-quantity plot. Statistics listed are percentiles of 1) the whole model height field, 2) m=model at validation sites, 3) model error m-o and 4) o=observed values. $\langle|\mathrm{m}-\mathrm{o}|\rangle$ is the Mean of the Absolute value of $\mathbf{m - 0}$. $\langle\mathrm{m}-\mathrm{o}\rangle$ is the mean error, or bias. $\langle\mathrm{m}\rangle$ and $\langle 0\rangle$ are the mean modelled and observed amplitudes. A log scale is used, starting at $10 \mathrm{~cm}$, so not all points can be shown. 




230 Figure 4 M2 height phase (otherwise like Fig. 3, except the y-axis of the inset is the phase error rather than phase). 
Table 2: Tidal height and phase region-average statistics, for 6 constituents (and their root sum of squares).

Height (cm)

mean observed amplitude $\langle 0\rangle$

\begin{tabular}{lllllllllllllll} 
& Aust & Arnhem GOC & \multicolumn{1}{c}{ Torres CGBR SGBR SEQ } & NSW & Bass & Tas & SA & SW & Pilbara Kimb. \\
\#sites & 615 & 78 & 111 & 67 & 59 & 67 & 29 & 27 & 54 & 24 & 62 & 31 & 41 & 43 \\
M2 & 72.5 & 112.1 & 59.2 & 60 & 56.5 & 112.4 & 59.7 & 46.5 & 56.7 & 46.5 & 25.5 & 6.6 & 77.5 & 168.3 \\
S2 & 35.8 & 50.1 & 34.7 & 41.1 & 33 & 42.2 & 17.5 & 11.1 & 12.1 & 7 & 26.7 & 7 & 44.4 & 99.5 \\
N2 & 16 & 21.7 & 18.3 & 20.8 & 18.6 & 27.7 & 11.8 & 10.5 & 11.8 & 9.3 & 1.9 & 2.1 & 11.8 & 26.5 \\
K1 & 29.6 & 42.2 & 42 & 47.2 & 31.4 & 31.9 & 18.9 & 15 & 15.9 & 17.3 & 24.2 & 17.5 & 21.2 & 31.6 \\
O1 & 17.6 & 27.1 & 24.3 & 23.9 & 15.1 & 16.4 & 10.6 & 9.4 & 10.9 & 12 & 16.5 & 12.6 & 13.6 & 19.3 \\
P1 & 8.5 & 11.7 & 12.2 & 13.7 & 9.4 & 9.6 & 5.1 & 4.5 & 4.8 & 4.2 & 7 & 5.4 & 5.9 & 8.7 \\
RSS & 89.7 & 134.9 & 86.9 & 93.3 & 77 & 128.6 & 67.2 & 52.2 & 62.4 & 52.5 & 47.6 & 24.4 & 93.7 & 200.9
\end{tabular}

240 mean magnitude of vector error (MMVE)

Aust Arnhem GOC Torres CGBR SGBR SEQ NSW Bass Tas SA SW Pilbara Kimb.

$\begin{array}{lllllllllllllll}\text { \#sites } & 615 & 78 & 111 & 67 & 59 & 67 & 29 & 27 & 54 & 24 & 62 & 31 & 41 & 43 \\ \text { M2 } & 20 & 36.4 & 20.2 & 20.6 & 7 & 23.3 & 17.1 & 6.2 & 12.8 & 7.9 & 9.6 & 1.7 & 23.5 & 55.9 \\ \text { S2 } & 12.9 & 22.6 & 14.3 & 19.3 & 4.6 & 9.5 & 7 & 2.4 & 3.4 & 2.9 & 11.2 & 1.1 & 17.3 & 42.1 \\ \text { N2 } & 5.1 & 7.4 & 6.7 & 8 & 3 & 7.3 & 3.8 & 1.7 & 3.5 & 3.6 & 0.92 & 0.6 & 5.2 & 11.5 \\ \text { K1 } & 7.7 & 19.1 & 14 & 17.7 & 2.1 & 3.3 & 3.9 & 2.5 & 3 & 3.8 & 5.6 & 2.6 & 5.3 & 7 \\ \text { O1 } & 4.6 & 11.3 & 8.9 & 10.2 & 1 & 1.9 & 2.2 & 1.5 & 1.9 & 2.3 & 3.4 & 2 & 3.1 & 4.2 \\ \text { P1 } & 2.5 & 5.2 & 4.8 & 6.1 & 0.84 & 1.1 & 1.7 & 0.87 & 1.1 & 2.4 & 1.7 & 1.1 & 2 & 2.2 \\ \text { RSS } & 26.1 & 49 & 30.9 & 36.2 & 9.2 & 26.5 & 19.4 & 7.5 & 14.2 & 10.5 & 16.3 & 4.1 & 30.3 & 71.4 \\ \text { \%obs } & 29.1 & 36.4 & 35.6 & 38.9 & 11.9 & 20.6 & 28.9 & 14.4 & 22.8 & 19.9 & 34.2 & 16.8 & 32.4 & 35.5\end{array}$

\begin{tabular}{|c|c|c|c|c|c|c|c|c|c|c|c|c|c|c|}
\hline \multirow[b]{2}{*}{ \#sites } & \multirow{2}{*}{$\begin{array}{c}\text { Aust } \\
615\end{array}$} & \multicolumn{2}{|c|}{ Arnhem GOC } & \multicolumn{4}{|c|}{ Torres CGBR SGBR SEQ } & \multirow{2}{*}{$\begin{array}{l}\text { NSW } \\
27\end{array}$} & \multirow{2}{*}{$\begin{array}{l}\text { Bass } \\
54\end{array}$} & \multirow{2}{*}{$\begin{array}{l}\text { Tas } \\
24\end{array}$} & \multirow{2}{*}{$\begin{array}{c}\text { SA } \\
62\end{array}$} & \multirow{2}{*}{$\begin{array}{l}\text { SW } \\
31\end{array}$} & \multicolumn{2}{|c|}{ Pilbara Kimb } \\
\hline & & 78 & 111 & 67 & 59 & 67 & 29 & & & & & & 41 & 43 \\
\hline M2 & 9.3 & 17.7 & 10.9 & 8.9 & 5.4 & 12.4 & 6.2 & 4.8 & 8 & 3.4 & 7.2 & 0.78 & 6.1 & 12.6 \\
\hline $\mathrm{S} 2$ & 5.7 & 10.2 & 8.3 & 11 & 2.4 & 4.8 & 3.5 & 2.2 & 2.1 & 1.3 & 7.9 & 0.6 & 4.3 & 7.9 \\
\hline $\mathrm{N} 2$ & 3 & 4.4 & 3.9 & 4.3 & 1.9 & 4.7 & 2 & 1.2 & 2.5 & 2.4 & 0.53 & 0.42 & 2.9 & 4.7 \\
\hline $\mathrm{K} 1$ & 3.5 & 4.7 & 8.1 & 9.3 & 1.6 & 1.5 & 1.6 & 1.9 & 2.3 & 2.1 & 3.2 & 1.2 & 2.1 & 2.7 \\
\hline $\mathrm{O} 1$ & 1.9 & 2.6 & 3.7 & 3.2 & 0.75 & 1.2 & 0.75 & 0.91 & 1.4 & 1.4 & 1.7 & 0.88 & 1.3 & 1.8 \\
\hline $\mathrm{P} 1$ & 1.3 & 1.7 & 2.6 & 3 & 0.62 & 0.54 & 0.97 & 0.67 & 0.86 & 2.1 & 0.97 & 0.5 & 1.1 & 1.2 \\
\hline RSS & 12 & 21.6 & 17 & 18 & 6.4 & 14.2 & 7.7 & 5.8 & 9 & 5.5 & 11.3 & 1.9 & 8.5 & 16 \\
\hline$\%$ obs & 13.4 & 16 & 19.6 & 19.3 & 8.4 & 11 & 11.4 & 11.1 & 14.5 & 10.4 & 23.8 & 7.8 & 9.1 & 8 \\
\hline
\end{tabular}

mean error $<$ m-o $>$ (bias)

Aust Arnhem GOC Torres CGBR SGBR SEQ NSW Bass Tas SA

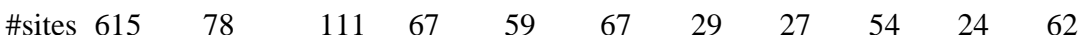

$\begin{array}{llllllllllll}\mathrm{M} 2 & -2.3 & -5.2 & -2.2 & -0.45 & 4.9 & -11 & 4.9 & 4.2 & -5.2 & -0.95 & -2.6\end{array}$

$\begin{array}{llllllllllll}\mathrm{S} 2 & -0.93 & 0.85 & -6.3 & -10 & 1.8 & -3.4 & 3.2 & 2.1 & -0.98 & -0.4 & 0.97\end{array}$

$\begin{array}{llllllllllll}\mathrm{N} 2 & -1.2 & -2.8 & -2.7 & -3.7 & 0.48 & -4.1 & 1.6 & 0.88 & -1.1 & 1.4 & 0.32\end{array}$

$\begin{array}{llllllllllll}\mathrm{K} 1 & -1.3 & -0.85 & -6.7 & -8.6 & 0.29 & -0.75 & 1.3 & 1.6 & 0.75 & 0.57 & -2.2\end{array}$

$\begin{array}{llllllllllll}\text { O1 } & -0.54 & -0.15 & -2.4 & -1.8 & 0.25 & -1.1 & 0.37 & 0.68 & 0.49 & 0.2 & -1.1\end{array}$

SW Pilbara Kimb.

$\begin{array}{lll}31 & 41 & 43 \\ -0.49 & 2.2 & -5 \\ -0.29 & 2.2 & -0.74 \\ -0.23 & 1.7 & -1.7 \\ 0.025 & 0.75 & 0.064 \\ 0.038 & 0.43 & -0.19\end{array}$


https://doi.org/10.5194/os-2020-107

Preprint. Discussion started: 11 December 2020

(c) Author(s) 2020. CC BY 4.0 License.

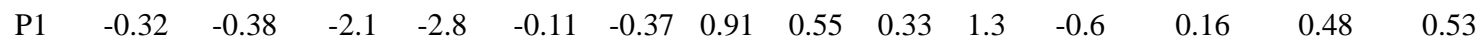

Height phase $\left(^{\circ}\right)$

mean absolute value of error $\langle|\mathrm{m}-\mathrm{o}|\rangle$ (MAE)

Aust Arnhem GOC Torres CGBR SGBR SEQ NSW Bass Tas SA SW Pilbara Kimb.

$\begin{array}{lllllllllllllll}\text { \#sites } & 615 & 78 & 111 & 67 & 59 & 67 & 29 & 27 & 54 & 24 & 62 & 31 & 41 & 43\end{array}$

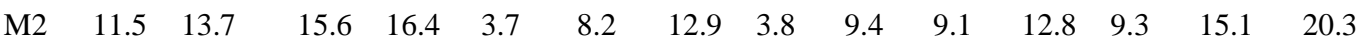

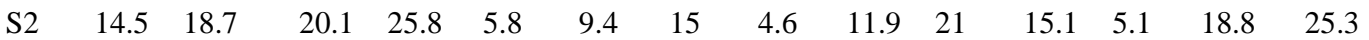

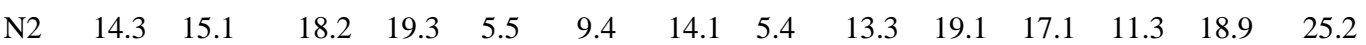

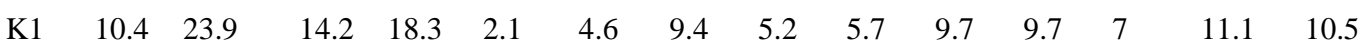

$\begin{array}{lllllllllllllll}\text { O1 } & 10.6 & 23 & 17.1 & 22.9 & 1.7 & 4.1 & 10.5 & 6.7 & 4.9 & 7.6 & 9.2 & 7.9 & 9.7 & 10.4\end{array}$

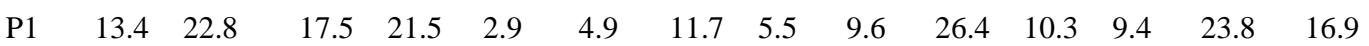

\begin{tabular}{|c|c|c|c|c|c|c|c|c|c|c|c|c|c|c|}
\hline \multirow[b]{2}{*}{ \#sites } & \multirow{2}{*}{$\begin{array}{c}\text { Aust } \\
615\end{array}$} & \multicolumn{2}{|c|}{ Arnhem GOC } & \multicolumn{4}{|c|}{ Torres CGBR SGBR SEQ } & \multirow{2}{*}{$\begin{array}{l}\text { NSW } \\
27\end{array}$} & \multirow{2}{*}{$\begin{array}{l}\text { Bass } \\
54\end{array}$} & \multirow{2}{*}{$\begin{array}{l}\text { Tas } \\
24\end{array}$} & \multirow{2}{*}{$\begin{array}{c}\text { SA } \\
62\end{array}$} & \multirow{2}{*}{$\begin{array}{c}\text { SW } \\
31\end{array}$} & \multicolumn{2}{|c|}{ Pilbara Kimb } \\
\hline & & 78 & 111 & 67 & 59 & 67 & 29 & & & & & & 41 & 43 \\
\hline M2 & 5.9 & 11.1 & 11.9 & 13.7 & 2.2 & 6.5 & -7.9 & -3 & 5.4 & 5.2 & -2.5 & 0.43 & 10.7 & 16 \\
\hline S2 & 7.1 & 13 & 11.5 & 12.1 & 5.4 & 7.5 & -7.4 & -3.6 & 6 & 1.3 & -0.39 & -1.1 & 15.6 & 19.7 \\
\hline $\mathrm{N} 2$ & 6.3 & 10.6 & 11.8 & 14.8 & 1.4 & 7 & -9.3 & -2 & 5.1 & -3 & 1.9 & 0.95 & 12.7 & 19.8 \\
\hline K1 & 6.2 & 23.4 & 9.4 & 17.3 & -0.44 & 4.3 & -5.7 & -3.3 & 1.2 & 0.94 & 3.2 & 3.1 & 7.7 & 7.9 \\
\hline O1 & 7 & 22.7 & 15.4 & 22.8 & 0.55 & 3.2 & -7.3 & -4.7 & 0.15 & 1.5 & 3.3 & 3.6 & 6.8 & 8.2 \\
\hline $\mathrm{P} 1$ & 3.7 & 21.7 & 11 & 20.5 & -1.4 & 3.9 & -6.5 & -4.4 & -2.4 & -19 & 4 & 0.9 & -4.3 & -2.4 \\
\hline
\end{tabular}




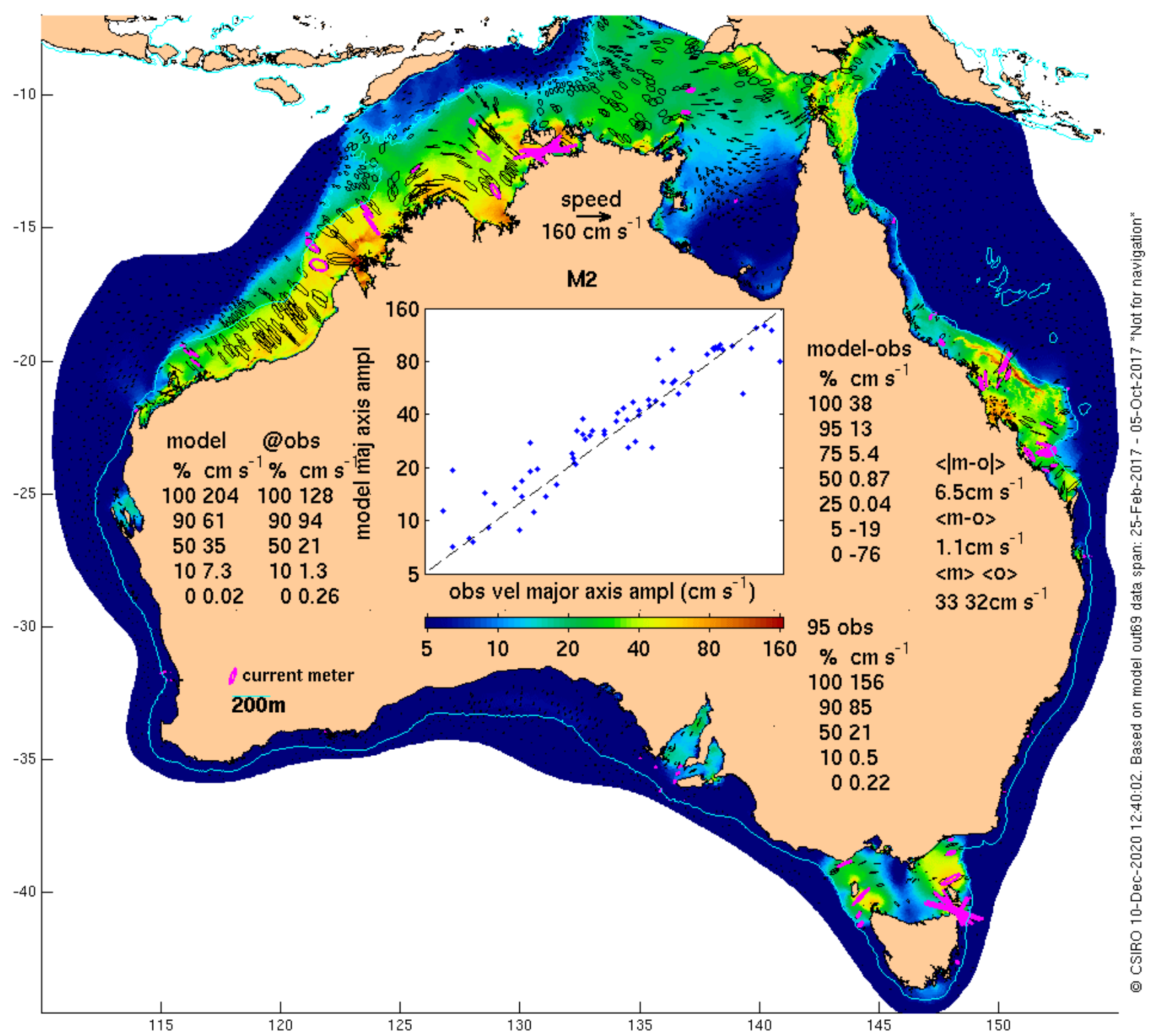

Figure 5 Amplitude of the M2 major axis velocity, otherwise like Fig. 3. Black (model, at a random subset of grid points) and magenta (observed) velocity ellipses use the scale shown.

\subsection{Tidal currents}

Perhaps the most striking difference between maps of the M2 major axis amplitude (Fig. 5) and the M2 height amplitude (Fig. 3 ) is that the currents have more small-scale variability, clearly associated with the local topography, as well as the regional variability that broadly reflects the regional variations of tidal range. Characterising and analysing the distribution of the errors 
https://doi.org/10.5194/os-2020-107

Preprint. Discussion started: 11 December 2020

as well as the signal is not straightforward, but is what we will attempt to do, after looking at some of the site-specific results listed in Table 3.

The first line of Table 3 is for a Gulf of Carpentaria site sampled in 1987 by CSIRO. It is the first line because it has the lowest reLF, which in turn is because the errors of the M2 major axis velocity phase and amplitude are both small $\left(0^{\circ}\right.$ and $\left.1 \mathrm{~cm} \mathrm{~s}^{-1}\right)$, while the amplitude of the observed M2 tidal currents is large $\left(21 \mathrm{~cm} \mathrm{~s}^{-1}\right)$ compared to the rms sub-tidal velocity $\left(3 \mathrm{~cm} \mathrm{~s}^{-1}\right)$. Site CW3 (line 2) sampled by Penesis et al. (2020) in Banks Strait is a much more energetic site but the errors of the major axis velocity phase and amplitude are both relatively small $\left(8^{\circ}\right.$ and $\left.1 \mathrm{~cm} \mathrm{~s}^{-1}\right)$ nevertheless. It is also a tidally dominated site, ( $98 \mathrm{~cm} \mathrm{~s}^{-1}$ for M2 compared to the sub-tidal velocity of just $7 \mathrm{~cm} \mathrm{~s}^{-1}$ ). As it happens, the error of the minor axis is also very small (both are essentially zero) here, but the error of the inclination is not $\left(-28^{\circ} \mathrm{T}\right.$ observed but $-52^{\circ} \mathrm{T}$ modelled). Site CW1 (line 3 ) is about $3 \mathrm{~km}$ away (just one grid cell) and has a greater amplitude error $\left(13 \mathrm{~cm} \mathrm{~s}^{-1}\right)$ but less inclination error $\left(3^{\circ}\right)$. Looking down the table we see that 9 of the 19 lowest-error sites are in Banks Strait. This is clearly a region where the model in its present form is capable of producing current velocity predictions with low relative error (reM2, re $\bar{M} 2$ and reLF 17, 26 and $30 \%$ at most), so is the first to be discussed in the next section.

At the other extreme (at the bottom of Table 3) is NRSNIN, an IMOS ADCP at the Ningaloo Reef National Reference Site in Western Australia, where the observed M2 major axis amplitude is just $7 \mathrm{~cm} \mathrm{~s}^{-1}$. The model estimate is listed as being more than twice this, at $19 \mathrm{~cm} \mathrm{~s}^{-1}$. From the prediction point of view, these errors are compounded by there being a fairly large $\left(18 \mathrm{~cm} \mathrm{~s}^{-1}\right)$ sub-tidal variance at this site. Similarly, the next-highest relative error is at GBRLSL, a site off the Great Barrier Reef in $330 \mathrm{~m}$ of water where the observed M2 major axis velocity is essentially zero, but the model estimate is $7 \mathrm{~cm} \mathrm{~s}^{-1}$. One thing these two sites have in common is that they are over steep topography where sharp gradients are common, so part of the poor agreement is bound to be due to representation error (that error that occurs when you compare a point measurement with an area-average). But even so, these are probably not sites where tidal predictions will be of much practical use.

Table 3 includes statistics that characterise model error averaged over sites grouped according to whether reLF is in the lowest, middle and highest third. The MAE over this first third is $7 \mathrm{~cm} \mathrm{~s}^{-1}$ (an $11 \%$ average relative error), while the MMVE is $13 \mathrm{~cm}$ $\mathrm{s}^{-1}$, a $22 \%$ average relative error or $29 \%$ if sub-tidal currents are taken into account as well. For the locations that these sites are representative of, you could argue that the tidal model is not only useful, but is enough by itself, i.e. a short-term forecast of sub-tidal current velocity would not often make a significant contribution (since its rms value is around $6 \mathrm{~cm} \mathrm{~s}^{-1}$, just $10 \%$ of the average M2 amplitude). For the middle group the average M2 tidal current amplitude ( $\left.30 \mathrm{~cm} \mathrm{~s}^{-1}\right)$ alone still exceeds the sub-tidal variability $\left(9 \mathrm{~cm} \mathrm{~s}^{-1}\right)$, but the dominance is less than for the first third and the errors of the tidal model are not insignificant. The average reLF for this group is $57 \%$, which could be argued as being acceptable, but with there being much room for reduction, either by improvements to the tidal model or addition in near-real time of a skilful forecast of sub-tidal variability. For the final third, the observed tidal currents are mostly insignificant ( $3 \mathrm{~cm} \mathrm{~s}^{-1}$ compared to $\left.22 \mathrm{~cm} \mathrm{~s}^{-1}\right)$, so it doesn't really matter what the predicted tidal velocity is, as long as it is weak. This last group includes all 11 sites in New South Wales and south-east Queensland regions, five of the deeper ( $100 \mathrm{~m}$ or more) sites in South Australia, and all eight of the sites in 
https://doi.org/10.5194/os-2020-107

Preprint. Discussion started: 11 December 2020

(c) Author(s) 2020. CC BY 4.0 License.

south-west Western Australia. We will now look more closely at the regions where tidal currents are a large fraction of the variability.

Table 3: Model errors for the M2 constituent at current meter sites. Columns: $h \_o$ and $h \_m$ are observed and modelled depth, |mean| and dir are the magnitude and direction of the mean observed velocity while sub_o is the rms observed sub-tidal velocity along its major axis. The modelled and observed major axis amplitudes are maj_m and maj_o (or $m$ and $o$ for short) so $m$-o is the amplitude error and normalising by o gives the relative error reM2. Taking phase into account we have $\mid \tilde{\text { m}}$-õ $\mid$, the magnitude of the vector error

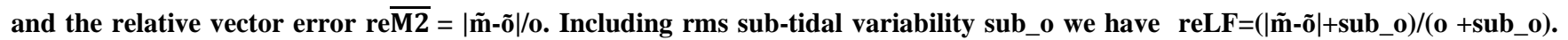
Sites are ordered by reLF. Averages over thirds and all of the sites are given.

\begin{tabular}{|c|c|c|c|c|c|c|c|c|c|c|c|c|c|c|c|c|c|c|c|c|c|}
\hline \& & 总 & 矛递 & $\dot{E}$ & $\underline{0}$ & $\hat{\theta}_{1}$ & $\begin{array}{l}\mathbf{\Xi}_{1} \\
\underline{\mathbf{E}}\end{array}$ & 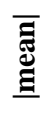 & $\doteq$ & $\begin{array}{l}\theta_{1} \\
\stackrel{\theta}{E}_{\tilde{n}}\end{array}$ & $\begin{array}{c}\theta_{1} \\
. ٍ \Xi\end{array}$ & $\frac{\bullet_{1}}{\overparen{\Xi}}$ & $\stackrel{\theta_{1}}{\Xi}$ & $\begin{array}{c}\Xi_{1} \\
. ٍ \\
.\end{array}$ & $\frac{\Xi}{\Xi}$ & $\begin{array}{l}\Xi_{1} \\
. \Xi\end{array}$ & $\stackrel{\mathfrak{i}}{\mathfrak{I}}$ & $\stackrel{\mathfrak{I}}{\mathbf{I}}$ & 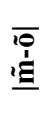 & 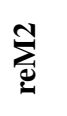 & 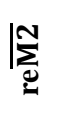 & 焉 \\
\hline & & & $\stackrel{\sim}{\infty}$ & 되 & $\boldsymbol{\Xi}$ & $\mathbf{\Xi}$ & Tn & H & تn & 5 & 'n & To & E- & 'n & 'n & 。 & In & T' & $s^{\circ}$ & $5^{2}$ & $a^{2}$ \\
\hline 1 & ARA-GOC87 & GOC & 10.64 & 136.94 & 57 & 58 & 7 & -42 & 3 & -86 & 21 & 6 & -79 & 22 & 1 & 0 & 1 & 1 & 6 & 6 & 17 \\
\hline 2 & CW3 & Bass & 40.55 & 148.08 & 33 & 31 & 4 & 115 & 7 & -28 & 98 & 0 & -52 & 98 & 1 & 8 & 1 & 14 & 1 & 14 & 20 \\
\hline 3 & CW1 & Bass & 40.53 & 148.06 & 32 & 30 & 0 & 90 & 0 & -52 & 81 & -2 & -55 & 94 & 1 & 7 & 13 & 16 & 16 & 20 & 20 \\
\hline 4 & CW4A1 & Bass & 40.67 & 148.09 & 30 & 32 & 6 & 84 & 9 & -71 & 133 & -3 & -70 & 128 & -1 & 9 & -6 & 21 & 4 & 16 & 21 \\
\hline 5 & ARA-GOC87 & GOC & 9.818 & 137.12 & 47 & 46 & 3 & 61 & 2 & 81 & 21 & 7 & 80 & 21 & 4 & -8 & 0 & 3 & 1 & 14 & 22 \\
\hline 6 & GBRHIN & SGBR & 23.38 & 151.99 & 45 & 41 & 3 & -33 & 8 & 78 & 50 & 8 & 80 & 45 & 6 & 1 & -5 & 5 & 10 & 10 & 22 \\
\hline 7 & CWTb1 & Bass & 40.68 & 148.23 & 63 & 45 & 16 & 128 & 9 & -68 & 87 & -3 & -69 & 99 & 0 & 4 & 11 & 13 & 13 & 15 & 22 \\
\hline 8 & CW2A1 & Bass & 40.58 & 148.1 & 44 & 33 & 9 & 121 & 11 & -50 & 123 & -3 & -54 & 123 & 0 & 9 & 0 & 20 & 0 & 16 & 23 \\
\hline 9 & ITFFTB & Arnhem & 12.29 & 128.48 & 108 & 105 & 4 & 121 & 6 & -52 & 35 & -7 & -54 & 37 & -7 & 5 & 2 & 4 & 6 & 11 & 23 \\
\hline 10 & NRSDAR & Arnhem & 12.34 & 130.71 & 18 & 16 & 3 & 79 & 4 & -59 & 55 & 7 & -60 & 60 & 8 & 9 & 5 & 10 & 9 & 19 & 24 \\
\hline 11 & BASS-CS91 & Bass & 40.14 & 144.25 & 53 & 50 & 3 & 42 & 10 & 46 & 58 & 7 & 47 & 53 & 7 & 5 & -6 & 7 & 10 & 13 & 26 \\
\hline 12 & CW2A2 & Bass & 40.7 & 148.2 & 44 & 39 & 12 & 156 & 7 & -38 & 85 & -2 & -60 & 95 & 0 & 9 & 10 & 18 & 12 & 21 & 27 \\
\hline 13 & C1A1 & Bass & 40.67 & 148.24 & 56 & 42 & 14 & 130 & 8 & -75 & 84 & -2 & -76 & 97 & 0 & 7 & 13 & 17 & 16 & 20 & 28 \\
\hline 14 & GBRHIS & SGBR & 23.51 & 151.96 & 47 & 45 & 2 & 40 & 4 & 88 & 32 & 2 & 83 & 37 & 5 & 5 & 5 & 6 & 15 & 18 & 28 \\
\hline 15 & CW4A2 & Bass & 40.73 & 148.34 & 36 & 36 & 7 & 87 & 5 & -72 & 66 & 14 & -75 & 70 & 11 & 12 & 3 & 15 & 5 & 22 & 28 \\
\hline 16 & DARBGF & Arnhem & 12.11 & 130.59 & 30 & 30 & 1 & -47 & 1 & -89 & 56 & 6 & -89 & 63 & 4 & 13 & 7 & 15 & 12 & 26 & 28 \\
\hline 17 & Darwin_C3 & Arnhem & 12.07 & 131.02 & 56 & 30 & 7 & 88 & 5 & 89 & 118 & -2 & 79 & 96 & 0 & 11 & -22 & 31 & 19 & 26 & 29 \\
\hline 18 & BASS-CS91 & Bass & 39.5 & 148.01 & 47 & 42 & 6 & 137 & 4 & 61 & 50 & 11 & 75 & 61 & 14 & 6 & 11 & 12 & 22 & 24 & 30 \\
\hline 19 & C1A3 & Bass & 40.69 & 148.12 & 27 & 25 & 12 & 12 & 8 & -75 & 144 & -1 & -67 & 119 & -1 & 12 & -24 & 37 & 17 & 26 & 30 \\
\hline 20 & North Rf & SGBR & 23.16 & 151.96 & 62 & 58 & 4 & 2 & 7 & -75 & 44 & 4 & -81 & 45 & 3 & 11 & 0 & 8 & 1 & 19 & 30 \\
\hline 21 & KIM100 & Kimberley & 15.68 & 121.3 & 99 & 96 & 5 & 213 & 11 & -49 & 40 & 13 & -53 & 39 & 13 & 7 & 0 & 5 & 0 & 12 & 31 \\
\hline 22 & KIM200 & Kimberley & 15.53 & 121.24 & 208 & 215 & 5 & 241 & 9 & -59 & 22 & 7 & -56 & 21 & 9 & 2 & -1 & 1 & 3 & 5 & 32 \\
\hline 23 & KIM050 & Kimberley & 16.39 & 121.59 & 59 & 56 & 3 & 257 & 8 & -72 & 44 & 26 & -74 & 48 & 28 & 11 & 4 & 10 & 10 & 22 & 33 \\
\hline 24 & DarwinCTbW & Arnhem & 12.02 & 130.97 & 22 & 22 & 9 & 234 & 2 & 65 & 89 & -1 & 85 & 93 & -1 & 21 & 3 & 34 & 4 & 38 & 39 \\
\hline 25 & CAM050 & Kimberley & 14.85 & 123.8 & 58 & 58 & 2 & 65 & 5 & -35 & 64 & 7 & -38 & 59 & 8 & 20 & -5 & 22 & 8 & 34 & 39 \\
\hline 26 & GBRCCH & SGBR & 22.41 & 151.99 & 93 & 87 & 6 & 123 & 7 & -70 & 28 & 0 & -67 & 32 & -1 & 10 & 4 & 7 & 14 & 24 & 39 \\
\hline
\end{tabular}




\begin{tabular}{|c|c|c|c|c|c|c|c|c|c|c|c|c|c|c|c|c|c|c|c|c|c|}
\hline 3 & 总 & 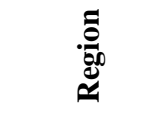 & E் & $\underline{0}$ & $\begin{array}{l}\theta_{1} \\
=\end{array}$ & $\begin{array}{l}\Xi \\
=\end{array}$ & 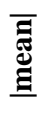 & 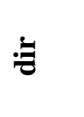 & $\begin{array}{l}\hat{\theta}_{1} \\
\stackrel{\hat{\sigma}^{\prime}}{\vec{n}}\end{array}$ & $\begin{array}{l}\text { إٍ } \\
.\end{array}$ & $\frac{0_{1}}{\ddot{Z}}$ & $\stackrel{\theta_{I}}{\Xi}$ & 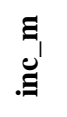 & $\begin{array}{l}\Xi_{1} \\
\stackrel{\Xi}{\Xi} \\
\stackrel{\Xi}{\Xi}\end{array}$ & $\begin{array}{l}\Xi_{1} \\
. \Xi \\
\Xi\end{array}$ & $\stackrel{i}{\mathfrak{I}}$ & $\stackrel{i}{\mathfrak{I}}$ & $\begin{array}{l}\bar{D} \\
\dot{I} \\
\underline{\underline{g}}\end{array}$ & 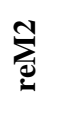 & 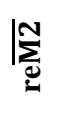 & 岳 \\
\hline & & & U & 되 & $\Xi$ & $\Xi$ & 'ָ & F- & Tn & 항 & $\stackrel{\infty}{0}$ & 跣 & $\stackrel{H}{H}$ & '心 & 'D & 。 & 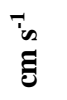 & ت & $b^{\circ}$ & $\delta^{2}$ & $2^{2}$ \\
\hline 7 & Darwin_CW2 & Arnhem & 12.06 & 130.95 & 34 & 30 & 8 & 61 & 4 & 73 & 83 & 0 & 75 & 94 & 3 & 18 & 11 & 30 & 13 & 37 & 39 \\
\hline 28 & BASS-CS91 & Bass & 3.91 & 43.54 & 64 & 56 & 2 & 81 & 8 & 67 & 38 & 4 & 82 & 47 & 2 & -7 & 10 & 11 & 25 & 29 & 41 \\
\hline s & C. Capricorn & SGBR & 23.51 & 151.29 & 26 & 27 & 2 & -56 & 9 & -37 & 39 & -7 & -38 & 28 & -5 & 2 & -11 & 11 & 27 & 27 & 42 \\
\hline 30 & TIMORS88 & Kimberley & 12.76 & 125.66 & 91 & 92 & 2 & 23 & 4 & 47 & 23 & -1 & 54 & 31 & 6 & -2 & 8 & 8 & 33 & 33 & 43 \\
\hline 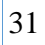 & GBROTE & SGBR & 23.48 & 52.17 & 60 & 61 & 4 & -22 & 17 & 70 & 29 & 10 & 74 & 31 & 2 & -2 & 2 & 2 & . & 9 & 43 \\
\hline 2 & ITFJBG & Arnhem & 13.61 & 128.97 & 61 & 56 & 1 & 226 & 4 & -29 & 34 & -10 & -30 & 44 & -18 & 11 & 10 & 12 & 28 & 36 & 43 \\
\hline me & an abs. value & $\mathrm{N}=32$ & & & 57 & 53 & & & 6 & & 62 & & & 63 & & 8 & 7 & 13 & 1 & 22 & 29 \\
\hline 33 & NW Shelf M6 & Pilbara & 19.74 & 116.39 & 65 & 64 & 3 & 112 & 6 & -54 & 25 & 5 & -43 & 32 & 3 & 6 & 7 & 8 & 27 & 30 & 43 \\
\hline 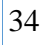 & CAM100 & Kimberley & 14.32 & 123.6 & 99 & 96 & 5 & 92 & 12 & -37 & 47 & 9 & -39 & 48 & 9 & 17 & 1 & 14 & . & 29 & 43 \\
\hline 5 & Darwin_CW3 & Arnhem & 11.95 & 131.23 & 22 & 20 & 9 & 98 & 3 & 46 & 76 & 7 & 49 & 87 & 2 & 21 & 11 & 32 & 14 & 41 & 44 \\
\hline 36 & CW6A1 & Bass & 40.43 & 148.54 & 37 & 33 & 16 & 35 & 9 & 22 & 36 & 7 & 27 & 26 & 8 & -10 & -10 & 11 & 27 & 3 & 45 \\
\hline 37 & Tas91UNSW & Bass & 40.84 & 144.14 & 95 & 93 & 3 & 111 & 4 & 27 & 15 & 6 & 34 & 19 & 8 & 0 & 5 & 5 & 31 & 3 & 47 \\
\hline 8 & Round Hill Hd & SGBR & 2 & 151.96 & 26 & 25 & 1 & 218 & 9 & -75 & 16 & 0 & -74 & 14 & 1 & -4 & -3 & 3 & 16 & 17 & 48 \\
\hline 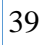 & BASS & Bass & & 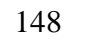 & 70 & 65 & 3 & -58 & 11 & 72 & 24 & 8 & 69 & 29 & 10 & $J$ & 6 & 6 & 24 & 24 & 48 \\
\hline 40 & BASS-UN91 & Bass & 41.18 & 144.23 & 115 & 116 & 5 & 151 & 6 & 42 & 14 & 8 & 33 & 11 & 4 & -9 & -3 & 4 & 22 & 26 & 49 \\
\hline 41 & SAM6IS & SA & 35.5 & 1366 & 83 & 85 & 3 & 188 & 8 & 57 & 9 & 0 & 55 & 9 & 1 & -5 & 0 & 1 & ? & 9 & 50 \\
\hline 2 & PIL050 & Pilbar & 05 & 116.42 & 55 & 52 & 2 & 268 & 12 & -50 & 25 & 4 & -48 & 30 & 1 & 6 & 6 & 6 & 22 & 25 & 50 \\
\hline 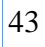 & $\mathrm{CW}$ & Bass & 40.43 & 8.53 & 31 & 33 & 4 & 9 & 6 & 46 & 45 & 4 & 27 & 26 & 8 & 7 & -19 & 20 & 42 & 43 & 50 \\
\hline 44 & PIL100 & Pilbara & 19.69 & 16.11 & 105 & 114 & 7 & 223 & 13 & -53 & 21 & 2 & -51 & 24 & 1 & 5 & 3 & 4 & 16 & 19 & 50 \\
\hline 45 & PIL200 & Pilbara & 19.44 & 115.92 & 208 & 239 & 8 & 231 & 11 & -73 & 13 & 0 & -64 & 14 & 0 & 0 & 1 & 1 & 7 & 7 & 51 \\
\hline 46 & Darwin_CW1 & Arnhem & 12.1 & 131.12 & 22 & 21 & 7 & 199 & 4 & -90 & 108 & 0 & -85 & 53 & 5 & 11 & -56 & 57 & 51 & 53 & 54 \\
\hline 7 & Dary & $\mathrm{Ar}$ & & 05 & 52 & 30 & 6 & 5 & 4 & 78 & 156 & -1 & 89 & 80 & 2 & 18 & -76 & os & 45 & & 55 \\
\hline 8 & Wigton I & $\mathrm{SC}$ & 87 & $\begin{array}{l}9.41 \\
\end{array}$ & 38 & 39 & 6 & 66 & 9 & -8 & 40 & 3 & -1 & 42 & 5 & 25 & 3 & 18 & 0 & 40 & 56 \\
\hline 49 & NRSYON & CGBR & 1 & 147.62 & 30 & 29 & 1 & -30 & 18 & -29 & 18 & 9 & -30 & 16 & 11 & 5 & -2 & 2 & 11 & 13 & 57 \\
\hline 50 & KIM400 & Kimberley & 15.22 & 121.11 & 396 & 371 & 1 & -85 & 7 & -64 & 10 & 5 & -57 & 12 & 2 & -6 & 3 & 3 & 2 & 30 & 59 \\
\hline 51 & ITFMHB & Arnhem & 11 & 128 & 146 & 130 & 1 & 74 & 9 & -34 & 14 & -6 & -36 & 19 & -4 & -8 & 5 & 5 & & 39 & 63 \\
\hline 2 & BASS-CS91 & Bass & 38 & 148 & 47 & 45 & 1 & 137 & 10 & 72 & 12 & 2 & 66 & 15 & 2 & -10 & 3 & 4 & 27 & 33 & 64 \\
\hline 53 & ARA-GOC87 & GOC & 13.99 & 139.03 & 60 & 62 & 2 & -2 & 3 & -54 & 7 & 4 & -64 & 7 & 3 & 27 & 1 & 3 & (3) & 50 & 65 \\
\hline 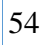 & GBRPPS & CGBR & 18.31 & 147.17 & 72 & 71 & 5 & 205 & 15 & 40 & 13 & 4 & 30 & 17 & 4 & 7 & 4 & 4 & 3 & 34 & 70 \\
\hline 55 & W Bugatti Rf & SGBR & 20.08 & 150.25 & 70 & 51 & 13 & 178 & 3 & 33 & 55 & 4 & 12 & 93 & 19 & 9 & 38 & 39 & . & 1 & 73 \\
\hline O & Brampton I & SGBR & 20.85 & 149.27 & 18 & 18 & 2 & 5 & 10 & -9 & 32 & -4 & -3 & 41 & 3 & 32 & 8 & 21 & 26 & 66 & 74 \\
\hline 57 & NRSKAI & SA & 35.83 & 136.45 & 103 & 110 & 12 & 192 & 20 & 17 & 8 & 0 & 14 & 8 & 1 & -8 & 0 & 1 & 6 & 14 & 76 \\
\hline 58 & GBRLSH & CGBR & 14.7 & 145.63 & 32 & 31 & 2 & -84 & 15 & 15 & 13 & 2 & 71 & 9 & 0 & -26 & -4 & 6 & 29 & 48 & 76 \\
\hline 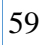 & N Bugatti Rf & SGBR & 20.03 & 150.3 & 64 & 47 & 12 & 54 & 7 & 19 & 48 & 8 & 46 & 83 & 7 & 6 & 35 & 36 & 73 & 74 & 78 \\
\hline J & TASE88 & Tas & 42.65 & 148.28 & 110 & 104 & 9 & 5 & 13 & -2 & 6 & 1 & -2 & 4 & 0 & -7 & -2 & 2 & 30 & 31 & 79 \\
\hline 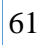 & SAM2CP & SA & 35.28 & 135.67 & 100 & 99 & 5 & -36 & 13 & 56 & 4 & 1 & 56 & 5 & 1 & -8 & 1 & 1 & 12 & 19 & 80 \\
\hline 0 & NRSMAI & Tas & 42.6 & 148.23 & 90 & 93 & 5 & 18 & 15 & -4 & 6 & 1 & -10 & 4 & 0 & 7 & -2 & 2 & 32 & 34 & 82 \\
\hline & SAM8SG & SA & 35.25 & 136.69 & 53 & 47 & 2 & 92 & 10 & 41 & 9 & 3 & 28 & 14 & 2 & -12 & 5 & 6 & 60 & 66 & 84 \\
\hline
\end{tabular}




\begin{tabular}{|c|c|c|c|c|c|c|c|c|c|c|c|c|c|c|c|c|c|c|c|c|c|}
\hline \multirow[t]{2}{*}{ 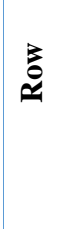 } & 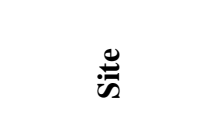 & 氮 & $\underline{\Xi}$ & $\stackrel{000}{0}$ & $\dot{\theta}_{1}$ & $\begin{array}{l}\Xi \\
=\end{array}$ & 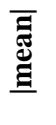 & $\doteq$ & $\begin{array}{l}\hat{\theta}_{1} \\
\stackrel{0}{\vec{n}}\end{array}$ & $\begin{array}{l}0^{\prime} \\
. \\
.\end{array}$ & $\frac{0_{1}}{\overparen{\Xi}}$ & $\stackrel{\mathfrak{o}_{1}}{\mathfrak{\Xi}_{\mathfrak{E}}}$ & $\begin{array}{c}\Xi \\
. \Xi \\
. \Xi\end{array}$ & $\frac{\Xi}{\Xi_{1}}$ & $\begin{array}{l}\Xi \\
\Xi \\
\Xi\end{array}$ & $\stackrel{i}{\mathfrak{I}}$ & $\stackrel{\mathfrak{I}}{\mathbf{I}}$ & 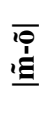 & 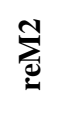 & 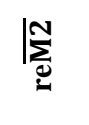 & 岳 \\
\hline & & & $\stackrel{\infty}{\infty}$ & 되 & $\Xi$ & $\boldsymbol{\Xi}$ & 范 & ${ }_{0}^{E}$ & تn & 훙 & 梁 & 管 & $\stackrel{+}{H}$ & 祭 & 梁 & $\circ$ & 战 & 战 & se & $b^{e}$ & $b^{2}$ \\
\hline & Creal Rf & SGBR & 20.5 & 150.4 & 69 & 69 & 3 & 230 & 3 & 17 & 23 & 8 & 17 & 38 & 9 & 27 & 15 & 20 & 63 & 86 & 88 \\
\hline & mean abs. value & $\mathrm{N}=32$ & & & 81 & 78 & & & 9 & & 30 & & & 29 & & 11 & 10 & 13 & 35 & 45 & 58 \\
\hline 65 & SAM5CB & SA & 34.93 & 135.01 & 98 & 95 & 2 & 104 & 23 & 15 & 3 & 1 & 14 & 3 & 1 & 1 & 1 & 1 & 27 & 27 & 93 \\
\hline 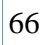 & GBRELR & SGBR & 21.04 & 152.89 & 305 & 316 & 48 & 116 & 41 & 53 & 5 & 1 & 86 & 6 & -1 & 11 & 1 & 2 & 27 & 35 & 93 \\
\hline 67 & SAM3MS & SA & 36.15 & 135.9 & 168 & 160 & 18 & 142 & 21 & 55 & 3 & 2 & 33 & 3 & 1 & -26 & 0 & 1 & 13 & 49 & 94 \\
\hline 68 & CH100 & SEQ & 30.26 & 153.4 & 97 & 92 & 31 & 199 & 37 & -14 & 2 & 1 & -72 & 2 & 1 & 13 & 0 & 1 & 6 & 25 & 96 \\
\hline 69 & ВMP070 & NSW & 36.19 & 150.19 & 74 & 61 & 10 & 182 & 17 & -21 & 1 & 0 & -30 & 1 & 1 & -20 & 0 & 0 & 18 & 41 & 96 \\
\hline 70 & $\mathrm{CH} 070$ & SEQ & 0.27 & 153.3 & 76 & 92 & 18 & 200 & 27 & -17 & 2 & 1 & -72 & 2 & 1 & 23 & 0 & 1 & 22 & 50 & 97 \\
\hline 71 & WATR04 & SW & 31.72 & 115.4 & 46 & 42 & 2 & -56 & 18 & 66 & 0 & 0 & 57 & 0 & 0 & -2 & 0 & 0 & 13 & 14 & 98 \\
\hline 72 & BMP120 & NSW & 36.21 & 150.32 & 121 & 125 & 14 & 173 & 35 & -29 & 1 & 0 & -47 & 2 & 1 & -3 & 0 & 0 & 38 & 39 & 98 \\
\hline 73 & GBRMYR & CGBR & 18.22 & 147.35 & 214 & 190 & 13 & 113 & 17 & 37 & 6 & 2 & 32 & 11 & 3 & -11 & 5 & 6 & 91 & 95 & 99 \\
\hline 74 & NRSROT & SW & 32 & 115.42 & 47 & 42 & 1 & 180 & 32 & 59 & 1 & 0 & 78 & 1 & 0 & -3 & 0 & 0 & 30 & 31 & 99 \\
\hline 75 & SAM7DS & SA & 50.2 & 135.84 & 519 & 587 & 7 & 150 & 11 & 54 & 1 & 1 & 33 & 2 & 0 & -38 & 1 & 1 & 46 & 00 & 99 \\
\hline 76 & L Musgrave I & SGBR & 23.93 & 152.3 & 42 & 42 & 3 & 166 & 5 & 85 & 14 & 2 & 62 & 28 & 4 & 1 & 14 & 14 & 99 & 99 & 99 \\
\hline 77 & SYD140 & NSW & 34 & 151.45 & 138 & 144 & 16 & 205 & 27 & 10 & 2 & 1 & -20 & 2 & 1 & 42 & 0 & 1 & 22 & 82 & 99 \\
\hline 78 & SYD100 & NSW & 330 & 151.38 & 103 & 117 & 14 & 199 & 26 & 5 & 2 & 1 & -18 & 2 & 1 & 39 & 1 & 1 & 6 & 86 & 99 \\
\hline 79 & WA & SW & 0 & 115.23 & 199 & 212 & 9 & 168 & 20 & 41 & 0 & 0 & 76 & 0 & 0 & 3 & 0 & 0 & 17 & 67 & 100 \\
\hline 80 & WATR50 & SW & 31.76 & 114.96 & 497 & 469 & 6 & 170 & 15 & 0 & 0 & 0 & 25 & 0 & 0 & 61 & 0 & 0 & 18 & 111 & 100 \\
\hline 81 & WATR20 & SW & 31.73 & 115.04 & 205 & 167 & 16 & 169 & 28 & 11 & 0 & 0 & 47 & 0 & 0 & 66 & 0 & 0 & 32 & 128 & 100 \\
\hline 82 & NRSESP & SW & 33.93 & 121.85 & 50 & 44 & 1 & 107 & 5 & 44 & 0 & 0 & 58 & 1 & 0 & -18 & 0 & 0 & 95 & 104 & 100 \\
\hline 83 & PH100 & NSW & 34.12 & 151.23 & 110 & 123 & 7 & 224 & 21 & 29 & 1 & 1 & -7 & 1 & 1 & 58 & 0 & 1 & 24 & 111 & 101 \\
\hline 84 & WATR15 & SW & 31.69 & 115.13 & 150 & 160 & 10 & 165 & 26 & -1 & 0 & 0 & 43 & 0 & 0 & 88 & 0 & 0 & 29 & 160 & 101 \\
\hline 85 & SAM4CY & SA & 36.53 & 136.87 & 117 & 105 & 0 & -30 & 22 & 18 & 1 & 0 & 31 & 2 & 1 & 16 & 1 & 1 & 131 & 137 & 101 \\
\hline 86 & WATR10 & SW & 1.65 & 115.2 & 107 & 79 & 9 & 150 & 18 & -42 & 0 & 0 & 50 & 0 & 0 & -8 & 0 & 1 & 125 & 256 & 102 \\
\hline 87 & SEQ400 & SEQ & 27.33 & 153.88 & 400 & 373 & 28 & 183 & 39 & -81 & 1 & 0 & 80 & 2 & 1 & -20 & 1 & 2 & 113 & 309 & 104 \\
\hline 88 & SEQ200 & SEQ & 27.34 & 153.77 & 200 & 203 & 23 & 178 & 44 & -73 & 1 & 0 & 85 & 3 & 2 & -43 & 1 & 4 & 111 & 292 & 105 \\
\hline 89 & BMP090 & NSW & 36.19 & 150.23 & 91 & 96 & 20 & 172 & 19 & 26 & 1 & 0 & -36 & 1 & 0 & -138 & 1 & 2 & 89 & 272 & 106 \\
\hline 90 & SAM1DS & SA & 36.52 & 136.24 & 520 & 587 & 5 & 114 & 10 & -13 & 0 & 0 & 32 & 1 & 0 & 17 & 1 & 1 & 455 & 460 & 109 \\
\hline 91 & NRSNSI & SEQ & 27.34 & 153.56 & 65 & 63 & 25 & 159 & 33 & 83 & 3 & 1 & 85 & 9 & 3 & -13 & 6 & 6 & 221 & 225 & 110 \\
\hline 92 & Tern I & SGBR & 20.85 & 149.98 & 47 & 50 & 8 & 141 & 7 & 28 & 22 & 1 & 6 & 32 & 5 & 60 & 11 & 29 & 48 & 131 & 123 \\
\hline 93 & ITFTIS & Arnhem & 9.818 & 127.55 & 464 & 534 & 2 & 223 & 7 & 83 & 8 & 1 & -79 & 8 & 2 & 4 & 0 & 16 & 3 & 203 & 154 \\
\hline 94 & GBRLSL & CGBR & 14.34 & 145.34 & 330 & 480 & 4 & -61 & 12 & 8 & 0 & 0 & 39 & 7 & 1 & 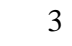 & 7 & 7 & 2395 & 2395 & 155 \\
\hline 95 & NRSNIN & Pilbara & 21.87 & 113.95 & 61 & 64 & 4 & 211 & 18 & 49 & 7 & 0 & -75 & 19 & -5 & 6 & 13 & 26 & 195 & 395 & 178 \\
\hline & an abs. value & $\mathrm{N}=31$ & & & 183 & 191 & & & 22 & & 3 & & & 5 & & 31 & 2 & 4 & 77 & 144 & 105 \\
\hline & an abs. value & $\mathrm{N}=95$ & & & 106 & 106 & & & 13 & & 32 & & & 33 & & 17 & 6 & 10 & 20 & 33 & 52 \\
\hline
\end{tabular}


https://doi.org/10.5194/os-2020-107

Preprint. Discussion started: 11 December 2020

(c) Author(s) 2020. CC BY 4.0 License.

310 Table 4: Tidal major axis velocity and phase region-average statistics, for six constituents (and their root sum of squares).

Velocity major axis amplitude $\left(\mathrm{cm} \mathrm{s}^{-1}\right)$

mean observed amplitude $<0>$

Aust Arnhem GOC CGBR SGBR SEQ NSW Bass Tas SA SW Pilbara Kimb.

\begin{tabular}{|c|c|c|c|c|c|c|c|c|c|c|c|c|c|}
\hline \#sites & 95 & 12 & 3 & 5 & 15 & 5 & 6 & 18 & 10 & 9 & 8 & 5 & \\
\hline M2 & 31.7 & 69.4 & 16.3 & 9.9 & 31.8 & 1.8 & 1.2 & 66.3 & 64.1 & 4.3 & 0.33 & 18 & 3 \\
\hline S2 & 11.3 & 33 & 5.3 & 5.3 & 12.9 & 0.44 & 0.41 & 10.2 & 9.1 & 4.6 & 0.4 & 11 & 21 \\
\hline $\mathrm{N} 2$ & 6.1 & 10.9 & 3.6 & 3.2 & 7.4 & 0.53 & 0.37 & 13.7 & 13.2 & 0.41 & 0.15 & 3 & \\
\hline $\mathrm{K} 1$ & 6.6 & 16.3 & 17.4 & 2.8 & 5.3 & 3.3 & 3.1 & 7.3 & 7.1 & 5.6 & 0.72 & 2.7 & \\
\hline $\mathrm{O} 1$ & 4 & 9.5 & 9.7 & 1.5 & 2.9 & 2.6 & 1.9 & 5.4 & 5 & 3.5 & 0.53 & 1.4 & \\
\hline $\mathrm{P} 1$ & 1.6 & 3.8 & 0 & 1.1 & 1.9 & 1.1 & 1.2 & 1.6 & 1.6 & 1.7 & 0.49 & 0.62 & \\
\hline RSS & 35.1 & 80 & 26.5 & 12.2 & 35.7 & 4.8 & 4.1 & 69.1 & 66.6 & 9.3 & 1.1 & 21.6 & \\
\hline
\end{tabular}

315 mean magnitude of vector error (MMVE)

Aust Arnhem GOC CGBR SGBR SEQ NSW Bass Tas SA SW Pilbara Kimb.

\begin{tabular}{|c|c|c|c|c|c|c|c|c|c|c|c|c|c|}
\hline \#sites & 95 & 12 & 3 & 5 & 15 & 5 & 6 & 18 & 10 & 9 & 8 & 5 & \\
\hline M2 & 10.3 & 27.4 & 2.5 & 5.1 & 14.7 & 2.7 & 1.1 & 13.9 & 13.3 & 1.6 & 0.3 & 8.9 & \\
\hline $\mathrm{S} 2$ & 4.6 & 15.1 & 2.2 & 3 & 5.8 & 1 & 0.47 & 2.7 & 2.3 & 1.9 & 0.54 & 5.2 & \\
\hline N2 & 2.2 & 4.6 & 0.88 & 1.7 & 3.6 & 0.73 & 0.27 & 3.3 & 3 & 0.25 & 0.12 & 1.6 & \\
\hline K1 & 4.7 & 14.8 & 6.7 & 1.6 & 3.8 & 2.6 & 3.8 & 3.7 & 4.8 & 2.8 & 0.82 & 2.1 & \\
\hline $\mathrm{O} 1$ & 2.8 & 7 & 6 & 0.95 & 2.4 & 2.3 & 2 & 2.9 & 3.5 & 1.7 & 0.55 & 1.2 & \\
\hline $\mathrm{P} 1$ & 1.7 & 3.5 & 4.6 & 0.58 & 1.4 & 1 & 1.4 & 2.3 & 2 & 0.85 & 0.6 & 0.91 & \\
\hline RSS & 12.8 & 35.8 & 10.7 & 6.4 & 16.9 & 4.7 & 4.7 & 15.4 & 15.2 & 4.2 & 1.3 & 10.7 & \\
\hline \%obs & 36.5 & 44.7 & 40.3 & 52.7 & 47.3 & 97.7 & 113.7 & 22.3 & 22.8 & 45.5 & 114.7 & 49.8 & \\
\hline
\end{tabular}

mean absolute value of error $\langle|\mathrm{m}-\mathrm{o}|>$ (MAE)

Aust Arnhem GOC CGBR SGBR SEQ NSW Bass Tas SA SW Pilbara Kimb.

\begin{tabular}{|c|c|c|c|c|c|c|c|c|c|c|c|c|c|}
\hline \#sites & 95 & 12 & 3 & 5 & 15 & 5 & 6 & 18 & 10 & 9 & 8 & 5 & \\
\hline M2 & 6.5 & 17.3 & 0.69 & 4.4 & 10.2 & 1.8 & 0.4 & 8.5 & 8 & 1.1 & 0.14 & 5.9 & \\
\hline $\mathrm{S} 2$ & 3 & 10.5 & 0.99 & 2.4 & 3.7 & 0.75 & 0.19 & 1.9 & 1.6 & 1.7 & 0.15 & 3.3 & \\
\hline $\mathrm{N} 2$ & 1.3 & 2.6 & 0.24 & 1.5 & 2.3 & 0.31 & 0.098 & 2.2 & 2 & 0.13 & 0.067 & 1 & .6 \\
\hline K1 & 2.3 & 4.9 & 3.3 & 1.1 & 1.8 & 2 & 2.4 & 2.8 & 3.1 & 1.9 & 0.24 & 53 & .8 \\
\hline O1 & 1.6 & 3.1 & 4.6 & 0.66 & 1 & 2 & 1.4 & 2.2 & 2.2 & 1.2 & 0.24 & 0.47 & 0.71 \\
\hline P1 & 1.1 & 1.3 & 4.6 & 0.38 & 0.69 & 0.68 & 0.99 & 2.1 & 1.6 & 0.64 & 0.26 & 0.45 & \\
\hline RSS & 7.8 & 21.2 & 7.4 & 5.4 & 11.3 & 3.5 & 3 & 9.9 & 9.3 & 3.1 & 0.48 & 6.8 & \\
\hline$\%$ obs & 22.3 & 26.6 & 27.9 & 44.2 & 31.7 & 73.3 & 72.1 & 14.3 & 14 & 33.8 & 41.7 & 31.7 & \\
\hline
\end{tabular}


https://doi.org/10.5194/os-2020-107

Preprint. Discussion started: 11 December 2020

(c) Author(s) 2020. CC BY 4.0 License.

mean error $<\mathrm{m-o}>$ (bias)

Aust Arnhem GOC CGBR SGBR SEQ NSW Bass Tas SA SW Pilbara Kimb.

$\begin{array}{lrrrrrrrrrrrrr}\text { \#sites } & 95 & 12 & 3 & 5 & 15 & 5 & 6 & 18 & 10 & 9 & 8 & 5 & 7 \\ \text { M2 } & 1.1 & -8.4 & 0.56 & 2.1 & 7.8 & 1.8 & 0.4 & 1 & 0.61 & 1 & 0.14 & 5.9 & 1.4 \\ \text { S2 } & 0.49 & -1.9 & 0.99 & 1.3 & 3 & 0.75 & 0.15 & -1.5 & -1.3 & 1.7 & 0.09 & 3.3 & 0.86 \\ \mathrm{~N} 2 & -0.05 & -1.6 & -0.22 & 0.29 & 1.5 & 0.19 & -0.064 & -0.79 & -1 & 0.096 & -0.007 & 1 & -0.26 \\ \text { K1 } & -0.83 & -0.2 & -2.1 & 0.34 & 0.66 & -2 & -2.4 & -2.2 & -3.1 & -1.5 & -0.000 & 0.5 & 0.71 \\ \text { O1 } & -0.52 & 0.036 & 3.7 & -0.1 & -0.32 & -1.9 & -1.4 & -1.8 & -2.1 & -0.65 & -0.042 & 0.47 & 0.71 \\ \text { P1 } & -0.04 & -0.092 & 4.6 & -0.14 & -0.21 & -0.68 & -0.99 & -0.02 & -0.35 & -0.52 & -0.26 & 0.34 & 0.5\end{array}$

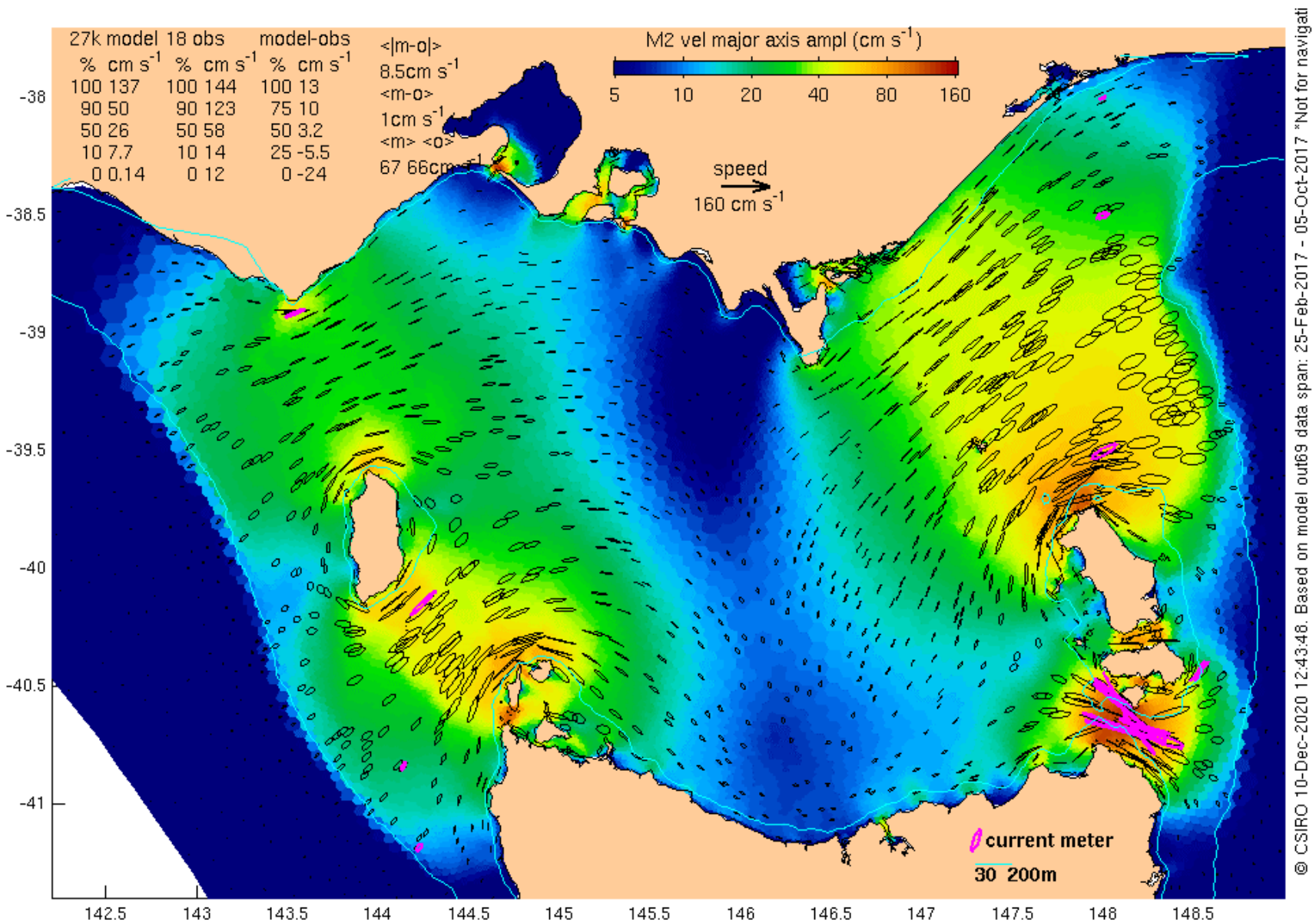

Figure 6 Amplitude of the M2 major axis velocity for Bass Strait, otherwise like Fig. 5, except that percentiles of the model at the locations of the observations are not listed. 


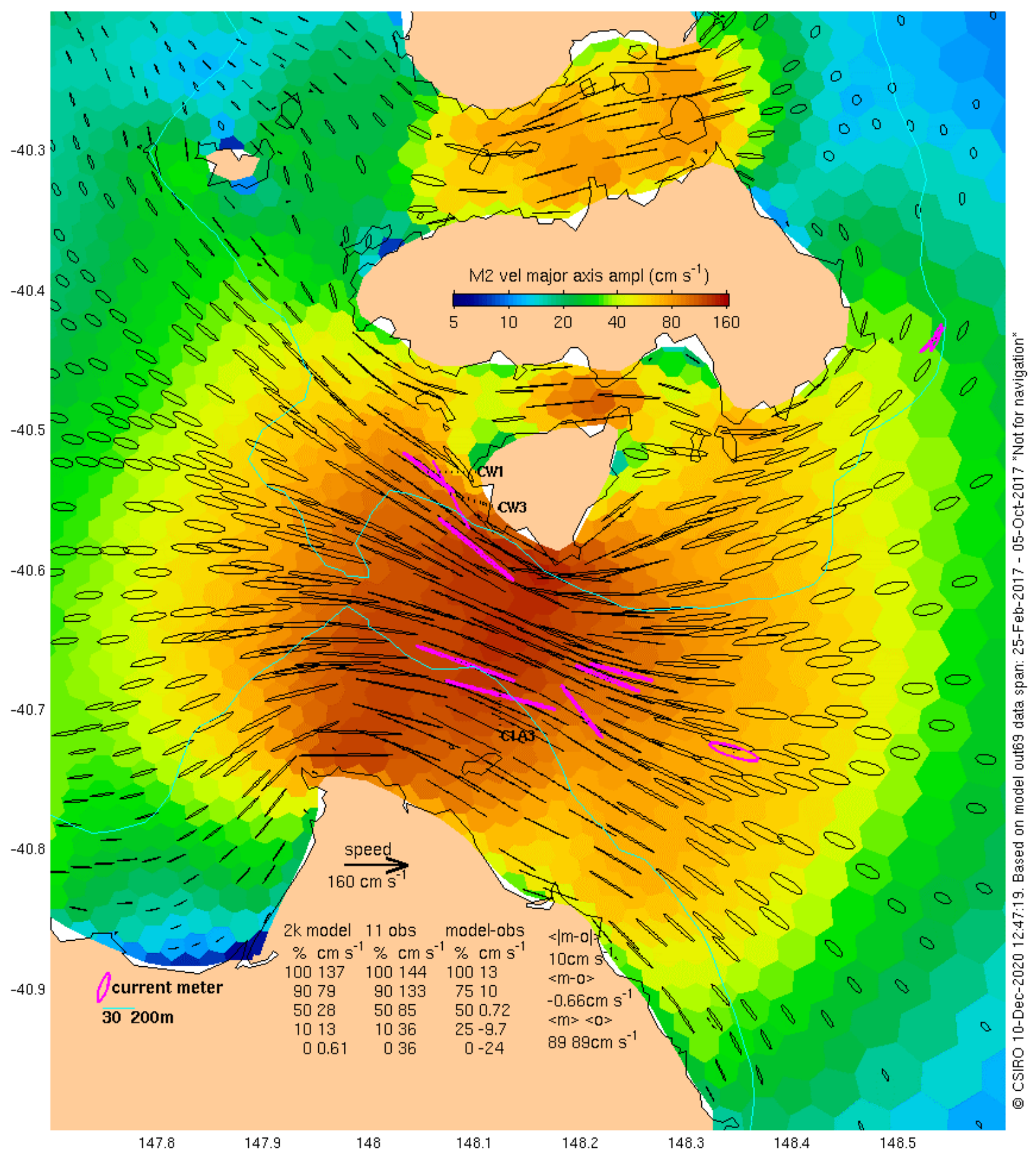

Figure 7 Amplitude of the M2 major axis velocity for Banks Strait, otherwise like Fig. 5. 
https://doi.org/10.5194/os-2020-107

Preprint. Discussion started: 11 December 2020

(c) Author(s) 2020. CC BY 4.0 License.

\subsubsection{Bass Strait (including Banks Strait)}

The tide comes into Bass Strait from both the east and west, with the strongest flows (Fig. 6) either side of the central basin (see Fig. 2) where the tidal range (Fig. 3) is a maximum. The highest tidal ranges are near Burnie on the northern Tasmanian coast. Recalling that tidal potential forcing is not activated in this run of the model, the agreement of our model with the observations is in contrast with the conclusion by Wijeratne et al. (2012) that tidal potential forcing is required for a nested model of Bass Strait to be accurate. We offer no explanation of this inconsistency. The greatest observed M2 major axis amplitude is $144 \mathrm{~cm} \mathrm{~s}^{-1}$ (at C1A3 in Banks Strait - see Fig. 7, one of the Penesis et al. (2020) ADCPs), where the model estimate is $119 \mathrm{~cm} \mathrm{~s}^{-1}$ (line 19 of Table 3). This is also the biggest error in Bass Strait, but it is still quite a small (17\%) relative 335 error. Taking the phase error also into account takes this to $26 \%$. Table 4 lists the M2 MAE across the 18 validation sites in Bass Strait as $8.5 \mathrm{~cm} \mathrm{~s}^{-1}$. The RSS across 6 constituents is $9.9 \mathrm{~cm} \mathrm{~s}^{-1}$, or $14.3 \%$ of the $69 \mathrm{~cm} \mathrm{~s}^{-1}$ mean observed RSS of amplitudes - a much better than average (22\% across Australia) relative error. Figure 6 and Table 3 show that, across Bass Strait, the modelled M2 current ellipse eccentricities and orientations are mostly in good agreement with observations. The phase errors range from $-10^{\circ}$ to $12^{\circ}$. Summing over six constituents, and taking the phase errors into account (Table 4), the

340 RSS MMVE is $15.4 \mathrm{~cm} \mathrm{~s}^{-1}$, or $22.3 \%$ of the mean observed RSS amplitude, making Bass Strait the region with the lowest relative error of RSS MMVE. 


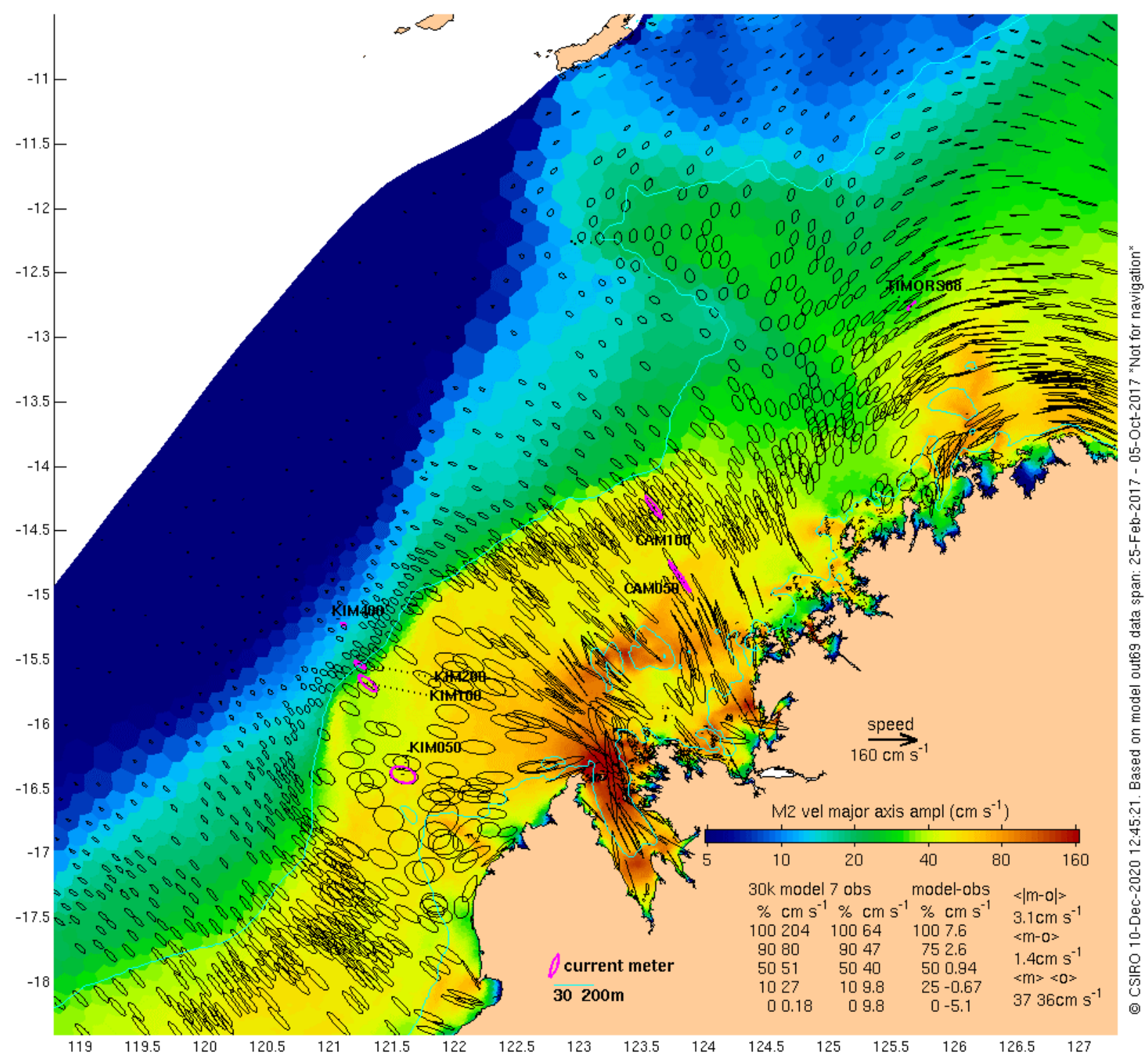

Figure 8 Amplitude of the M2 major axis velocity for the Kimberley, otherwise like Fig. 5.

\subsubsection{Kimberley}

345 The Kimberley region of Australia includes King Sound, where the greatest tidal range in Australia occurs. The entrance to King Sound has such strong tidal currents that tourists go out to see them in RIBs, helicopters and other vessels. There are not, however, any available instrumental records of the flows in the most energetic regions, so the percentiles of the model (across $\sim 30,000$ cells, see Fig. 8) are very different to the percentiles of the observations. Figure 8 shows that the model agrees quite well with the seven available records, including the change from nearly circular M2 ellipses at KIM050 to the shore-normal 
https://doi.org/10.5194/os-2020-107

Preprint. Discussion started: 11 December 2020

(c) Author(s) 2020. CC BY 4.0 License.

(c) (1)

350 rectilinear flows at CAM050 and CAM100, and then the shore-parallel ellipses at TIMORS88. The M2 amplitude errors at KIM200 and KIM100 are just 3 and $0 \%$ of the observed amplitude. It is only with the phase taken into account that the M2 relative errors are significant (5 and 12\%). The RSS MMVE is $11.4 \mathrm{~cm} \mathrm{~s}^{-1}$, or $27 \%$ of the observed RSS amplitude, just 5 points higher than the Bass Strait figure.

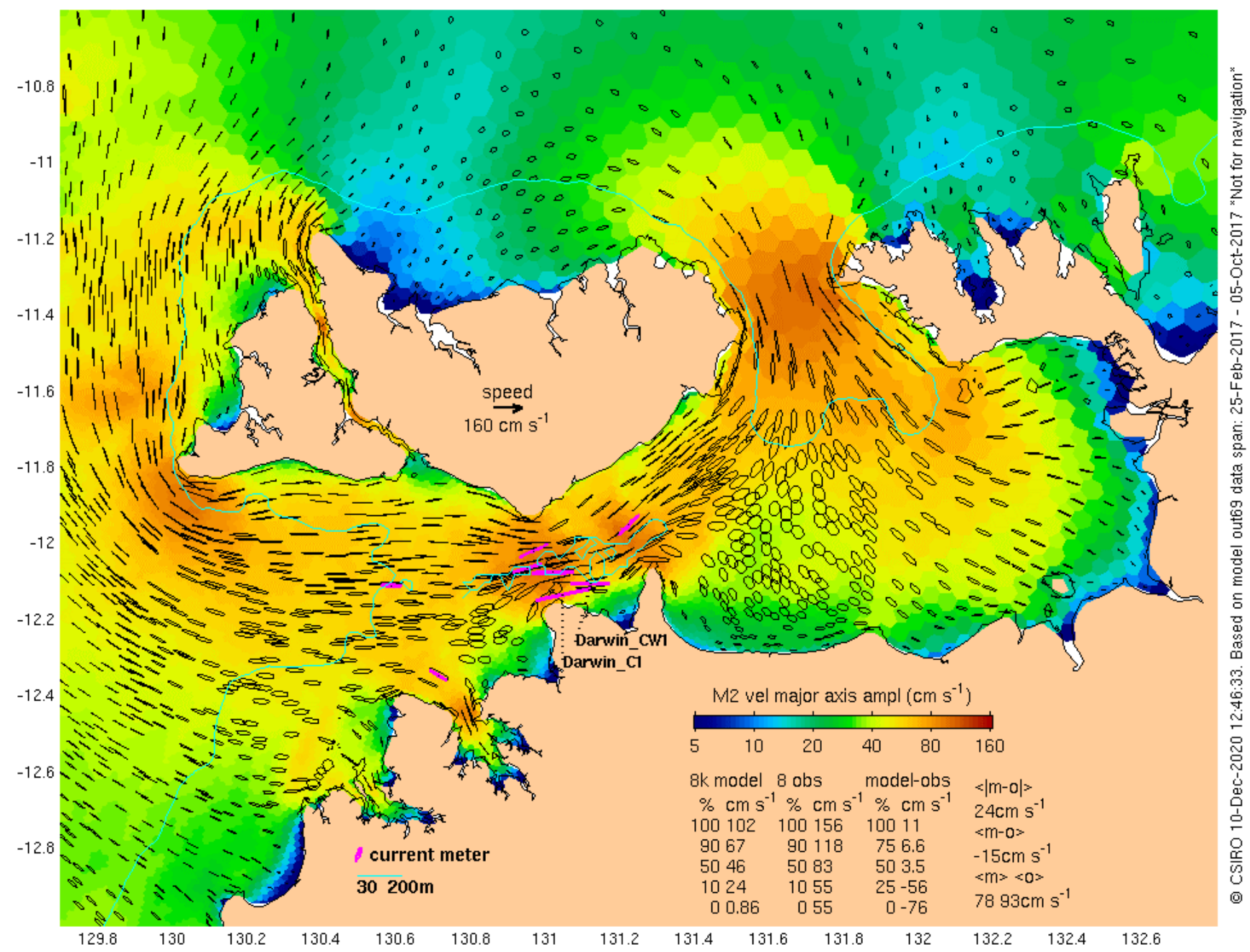

Figure 9 Amplitude of the M2 major axis velocity for the Darwin region, otherwise like Fig. 5. 


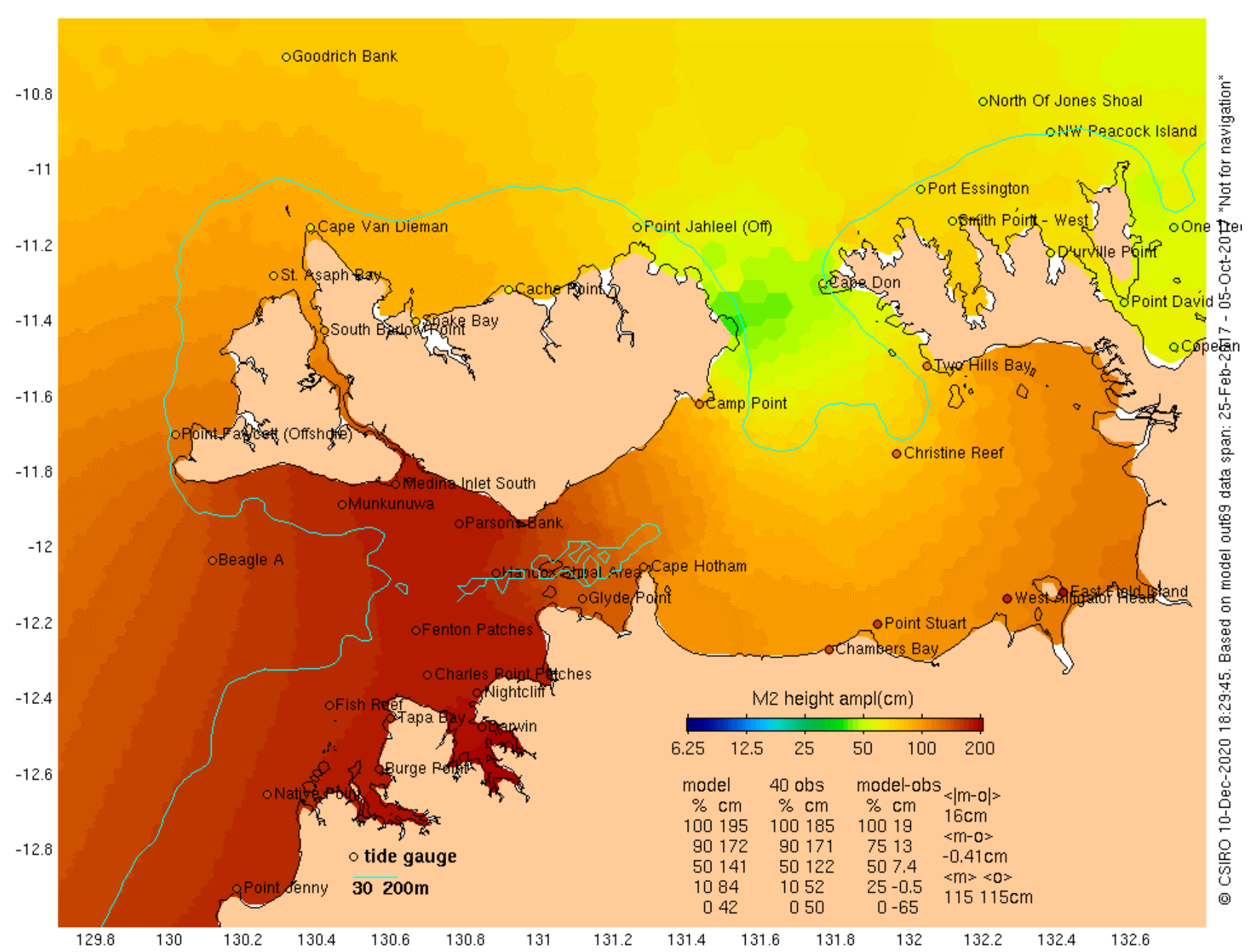

Figure 10 Amplitude of the M2 height for the Darwin region, otherwise like Fig. 3.

\subsubsection{Darwin}

Figure 9 shows that M2 velocity errors are relatively low at six of the eight sites in the Darwin-Clarence Channel region. Table

3 (lines 46 and 47) identifies the two noticeable exceptions as being the Darwin-CW1 and C1 sites, where the M2 major axis amplitude errors are 56 and $76 \mathrm{~cm} \mathrm{~s}^{-1}$. At $\mathrm{C} 1$ the problem is clearly the topography; model depth is only $8 \mathrm{~m}$ but the in situ depth is $52 \mathrm{~m}$. It is less clear why the error at CW1 is large but we will not be surprised if rebuilding the mesh using recentlyacquired topography data does not reduce these errors. At present however, the velocity major axis RSS MMVE remains listed as $35.8 \mathrm{~cm} \mathrm{~s}^{-1}$, or $44.7 \%$ of the observed RSS amplitude. The modelled tidal height amplitude in Van Diemen Gulf (Fig. 10, see Christine Reef for example) is significantly weaker than the observations, for reasons that we are yet to determine. 


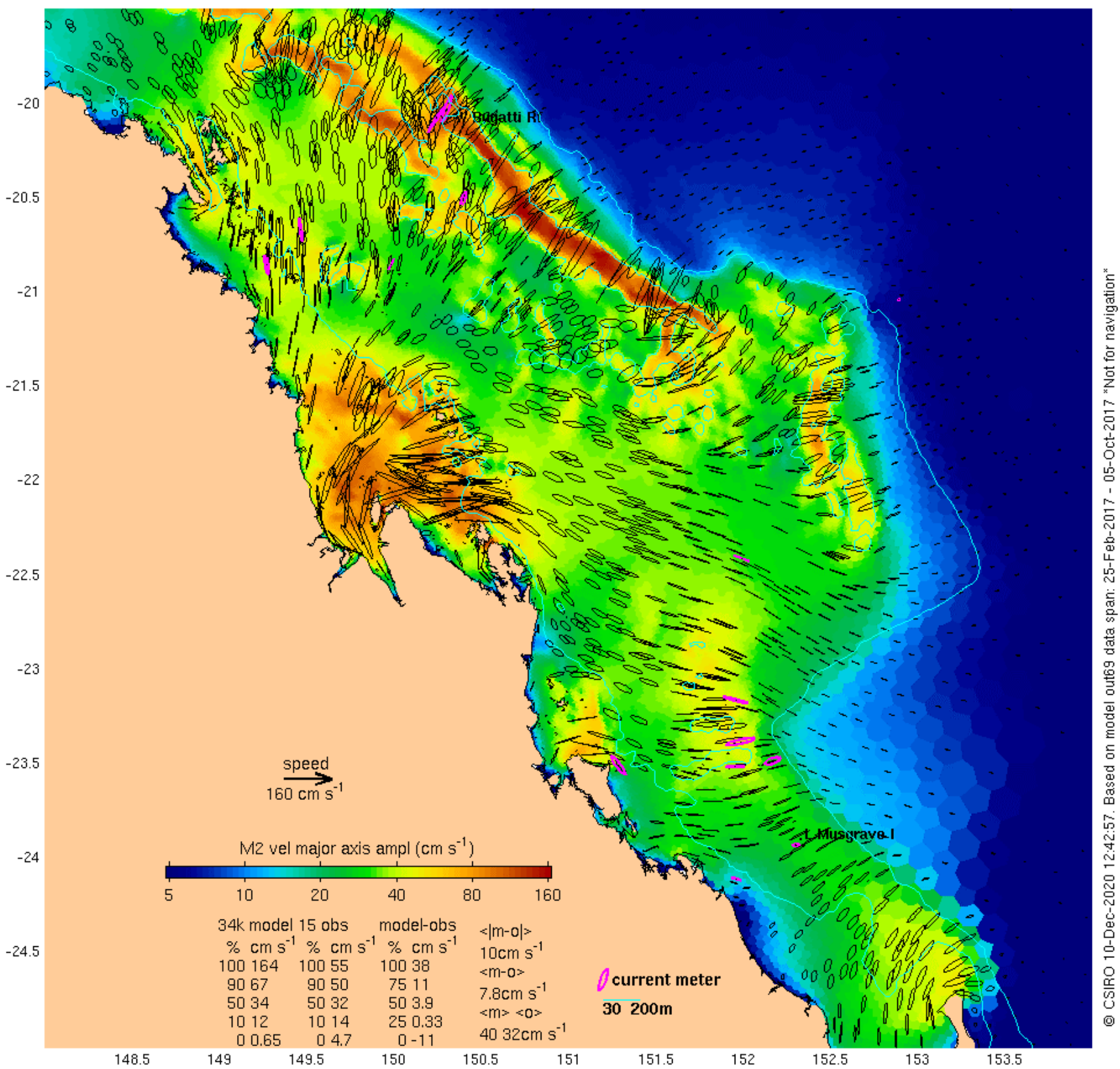

Figure 11 Amplitude of the M2 major axis velocity for the Southern Great Barrier Reef region, otherwise like Fig. 5.

\subsubsection{Southern Great Barrier Reef}

The Barrier Reef is dense off Broad Sound, causing tides to enter the reef lagoon from both the NW and SE. These waves meet

in the lagoon outside Broad Sound then further amplification of the wave entering the Sound occurs due to the geometry of the Sound (Middleton, Buchwald and Huthnance, 1984). Our model simulates the first process satisfactorily in a qualitative 
https://doi.org/10.5194/os-2020-107

Preprint. Discussion started: 11 December 2020

(c) Author(s) 2020. CC BY 4.0 License.

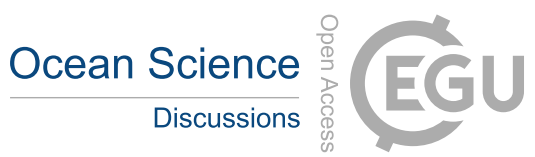

(c) (1)

sense (see Fig. 11), and the modelled and observed tidal currents are in very good agreement at many locations. But Table 4 also lists some large discrepancies at several sites. These are where the observations were made by mechanical current meters, some in topographically complex locations (two near Bugatti Reef, one near Lady Musgrave Island), so the listed RSS MMVE

375 of $16.9 \mathrm{~cm} \mathrm{~s}^{-1}$ (or $47.3 \%$ of the observed amplitude) possibly overstates the true error. The tide gauge (at McEwin Islet) near the head of the Sound (Fig. 3) suggests that the second amplification process is not well modelled, since the modelled range there is only about $75 \%$ of the observed range, and the modelled tide lags the observed tide by more than an hour. 


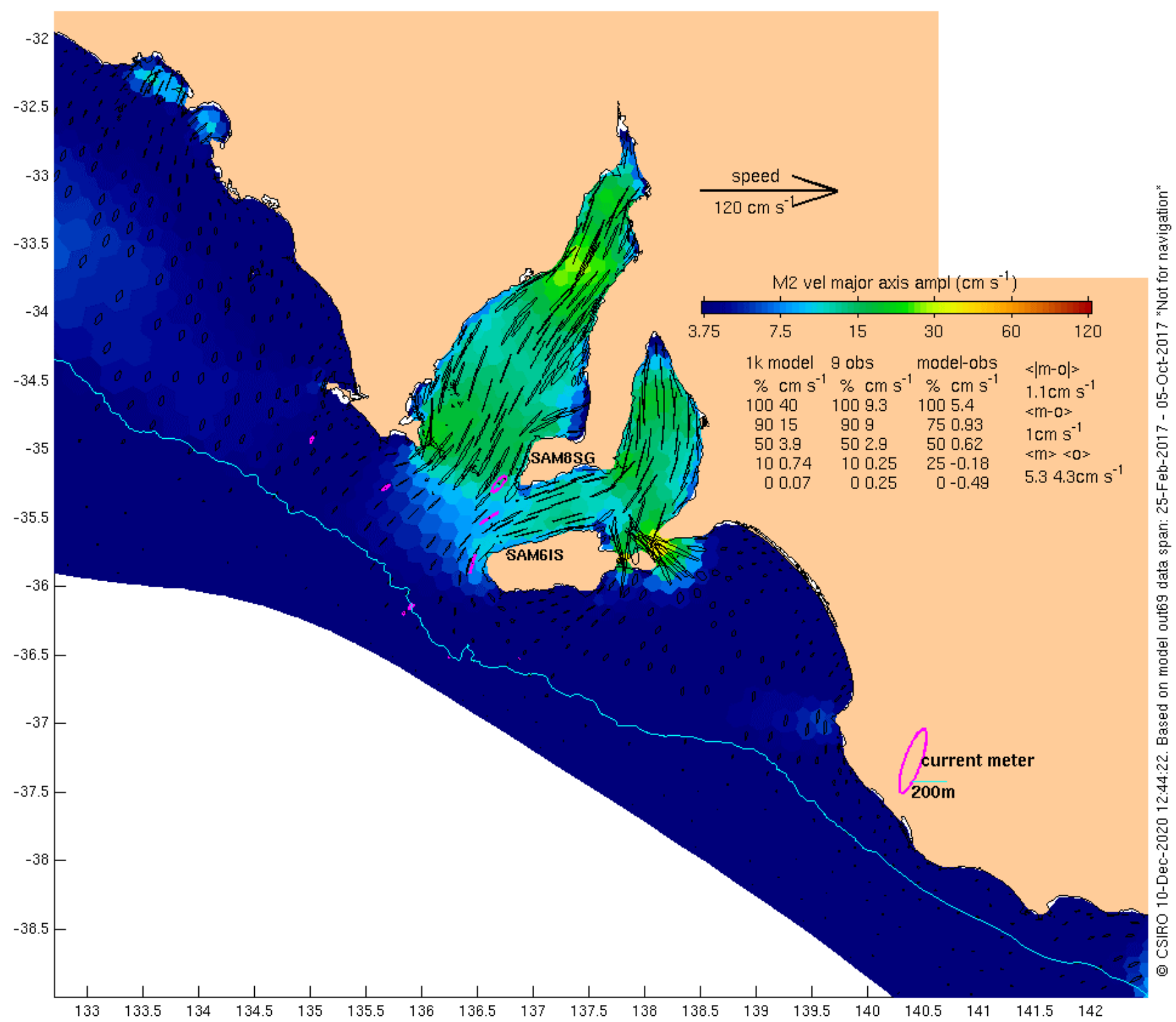

Figure 12 Amplitude of the M2 major axis velocity for the South Australia region, otherwise like Fig. 5.

\subsubsection{South Australia}

A distinctive feature of the tides of South Australia is that the amplitude of S2 exceeds that of M2 (barely), leading to a very strong spring-neap cycle. The vanishing semidiurnal tide on days when M2 and S2 are out of phase is locally known as the

385 Dodge tide. Table 2 lists the SA-average observed M2 and S2 height and major axis amplitudes as 25.6 and $26.7 \mathrm{~cm}$, and 4.3 and $4.6 \mathrm{~cm} \mathrm{~s}^{-1}$. The model M2 and S2 height and major axis amplitudes (not listed) are also nearly equal, at 23 and $28 \mathrm{~cm}$, and 5.3 and $6.2 \mathrm{~cm} \mathrm{~s}^{-1}$ so Dodge tides will also occur (imperfectly) in model-generated predictions. The maximum modelled M2 
major axis amplitude is $40 \mathrm{~cm} \mathrm{~s}^{-1}$ in the South Australian region (Fig. 12), but we have no observations to validate the model at that location. The maximum observed M2 major axis amplitude is $9.3 \mathrm{~cm} \mathrm{~s}^{-1}$ at both SAM6IS and SAM8SG (rows 41 and 63 of Table 3) where the model is in very close and moderate agreement, respectively. The RSS MMVE is $4.2 \mathrm{~cm} \mathrm{~s}^{-1}$, or $45.5 \%$ of the observed amplitude.

\subsubsection{Pilbara}

Table 3 lists results for just five sites in the Pilbara region (one being the Ningaloo site mentioned earlier as having the greatest error). Unfortunately, these are all we have in our validation dataset despite the economic importance of marine traffic in this region. Results for the three IMOS ADCPs near $20^{\circ} \mathrm{S}$ (PIL050, 100 and 200) include M2 vector errors of 7 to $25 \%$ of the observed amplitude. But this region is well known for strong internal tides (Book et al., 2016), to which our analysis method is essentially blind, and thus underestimates the errors. Internal tides aside, the RSS MMVE for this region is $10.7 \mathrm{~cm} \mathrm{~s}^{-1}$, or $49.8 \%$ of the observed amplitude.

\subsubsection{Gulf of Carpentaria, Torres Strait, Central Great Barrier Reef}

400 The GOC and CGBR regions have intermediate (40.3 and $52.7 \%$ ) relative errors of the RSS MMVE, but being based on just 3 and 5 sites, these statistics are uncertain. Nevertheless, we see value in publishing tidal current predictions for these two regions, with appropriate warnings, partly because the sub-tidal currents are weak in these two regions. As mentioned earlier, Torres Strait is one of the few places where official tidal current predictions are already published. We have not yet compared those predictions, or observation-based constituents with our model.

\subsubsection{South-east Queensland, New South Wales and South West}

The relative error of the RSS MMVE for the SEQ, NSW and SW regions are 98, 114 and $115 \%$, respectively, suggesting that the model is not simulating the tidal currents in these regions very well, even though it is simulating the heights (recall that NSW is one of the regions with the lowest relative error of height). These narrow-shelf regions are also where the sub-tidal currents (Table 3) far exceed the tidal currents, so predictions of tidal currents would be of limited practical value even if they were accurate. For both these reasons, we will not be publishing tidal current predictions from the COMPAS model for these regions.

\section{Discussion}

We have evaluated the tidal heights in our COMPAS model against a large number (615) of sites around Australia, giving a much more detailed picture than was given, for example, by Haigh et al. (2014) or Seifi et al. (2019), while being broadly 415 consistent. But modelling tidal heights is not the principal motivation of this study. Our focus is on tidal currents (depthaveraged at this point), about which much less has been written (Stammer et al., 2014; Timko et al., 2013). Lyard et al. (2020) 
compare FES2014 with the same IMOS data we have used (just graphically). They conclude that for shelf currents, there is still a need for nested regional models (such as ours), with finer grids than global models have.

We have shown that our COMPAS model of the barotropic tide is in very good agreement with observed tidal currents at many, but certainly not all, of the 95 sites at which we have in situ validation data. A large number of the sites with high relative errors are where the tides are very weak, so it could be argued that those errors are of little practical interest. Over the continental shelf, this is the case for the southern half of the continent from Ningaloo Reef in the west to Fraser Island in the east, excepting Bass Strait and the South Australian gulfs (i.e. the sections where the shelf is narrow). This leaves $79 \%$ by area of Australia's shelf waters as being where tidal currents are both predictable and a significant proportion of the total variance. Bass Strait and the Kimberley region are where our model performs best, with the root sum of square (across 6 constituents), regional-average vector error of the major axis velocity being less than $27 \%$ of the observed signal. This measure of the relative error of the model's tidal predictions is between 40 and $50 \%$ in the other regions where we think the predictions should be made available to the public.

We hope to expand our tidal currents validation dataset, especially at locations (mainly in the NW) where observations have been made by offshore industries, in order to guide development of the next version of our model. Incomplete as it is, we are publishing it now along with the output of our model because we are sure it will have enduring value, for example, to developers of global models such as Lyard et al (2020) who used a preliminary version of the validation dataset.

It is well established (e.g. by Ray et al., 2011) that accurate topography is an essential component of a good tidal model and our results and those of Sahuc et al. (2020) bear this out. Some of the largest model errors are where there is a big discrepancy

435 between the depth in the model and the depth that was recorded on site during mooring deployment. Improving the topography in our model is certainly a priority for future model development. This will likely comprise a combination of inverse tuning where local bathymetry alterations are made to optimally correlate model predictions to observation, and capitalising on the results of the ausSeabed initiative (http://www.ausseabed.gov.au/about).

Boundary conditions are also, of course, an essential input for a regional tidal model. We have only tested our model using open boundary forcing from TPXO9v1, but hope to test it soon using TPXO9v2 and FES2020.

\section{Conclusions}

We have shown that for many regions around Australia's continental shelf, our model can predict depth-averaged tidal currents with enough accuracy to arguably be operationally useful for mariners and maritime industries. Regions where tidal currents are most predictable and in excess of non-tidal currents include Bass Strait, the Kimberley, Joseph Bonaparte Gulf to Arnhem

445 Land and the southern Great Barrier Reef. Consequently, these are the regions for which we intend to commence publishing 'unofficial' predictions of tidal currents (both model-based and observation-based). They are also the regions of greatest interest to the renewable energy sector, for whom we have published maps based on the model discussed here. We intend also to publish tidal current predictions for the South Australian gulfs, the Pilbara, Gulf of Carpentaria, Torres Strait and the central 
https://doi.org/10.5194/os-2020-107

Preprint. Discussion started: 11 December 2020

(c) Author(s) 2020. CC BY 4.0 License.

(c) (i)

and northern Great Barrier Reef regions but with a warning that there may be greater errors in these regions. For the rest of Australia (comprising the narrow-shelf regions of the southern half of the continent) we see no need to publish tidal current predictions, largely because the non-tidal currents are dominant.

\section{Code Availability}

COMPAS is supported by CSIRO, Australia and available open source at https://github.com/csiro-coasts/EMS, with documentation provided at https://research.csiro.au/cem/software/ems/ems-documentation/. We appreciate the encouragement of the MPAS developers in pursuing this work.

\section{Data availability}

- Three project data sets have been published by Herzfeld, et al. (2020) https://doi.org/10.25919/nqdc-1v40 :

1. The first 59 of the 222 days of COMPAS output hourly time series, at all cell centers, for all state variables

2. harmonic constituents of the COMPAS velocity and height fields, derived from a 222 day model run so K1 and P1 are resolved

3. harmonic constituents of the currents validation dataset, along with subtidal ellipse parameters for 95 locations.

- COMPAS-based estimates of Australia's tidal energy resource are available at

1. https://nationalmap.gov.au/renewables/

- Current meter validation dataset timeseries are available at: https://portal.aodn.org.au/

- Graphics similar to the Figures in this paper showing constituents other than M2, other regions, other variables, and statistical properties of the tidal heights, energy fluxes, etc. http://www.marine.csiro.au/ griffin/ARENA tides/tides/

\section{Author contribution}

David Griffin assembled the validation data set, performed the model-data comparisons and prepared the manuscript, with contributions from coauthors. Mike Herzfeld developed and ran the COMPAS model. Mark Hemer led the main (ARENA) project that this study is part of, contributed to the analyses and maintained linkages with collaborators.

\section{Competing interests}

The authors declare that they have no conflict of interest.

\section{Disclaimer}

The data products of this research are not for navigation. The work is only a step towards an operational product. 
https://doi.org/10.5194/os-2020-107

Preprint. Discussion started: 11 December 2020

This work was performed as part of three projects: 1) the Australian Tidal Energy (AUSTEn) project funded by the Australian Renewable Energy Agency (ARENA) Advancing Renewables Program under agreement number G00902, 2) the CSIRO, Bureau of Meteorology and Royal Australian Navy Bluelink project and 3) the CSIRO Australian National Modelling Initiative. Tidal constituents for 683 tide gauge sites were kindly provided by the National Operations Centre (NOC) Tidal 480 Unit of the Bureau of Meteorology, who also provided helpful comments on the work as it progressed, and the resulting paper. Current meter data were provided at 55 sites by Australia's Integrated Marine Observing System (IMOS), which is enabled by the National Collaborative Research Infrastructure Strategy (NCRIS). IMOS is operated by a consortium of institutions as an unincorporated joint venture, with the University of Tasmania as Lead Agent. Topography data were supplied by Geosciences Australia and the Naval Research Laboratory Digital Bathymetry Data Base. Global tidal constituents from the TPXO model

485 were provided by Lana Erofeeva and Gary Egbert. Thanks to Darren Engwirda for his assistance with generating the unstructured mesh and integrating JIGSAW into the modelling framework. We also thank several colleagues for comments on the manuscript, including Madeleine Cahill, James Chittleborough, Andy Taylor and Clothilde Langlais.

\section{References}

Beaman, R. J.: Project 3DGBR: A high-resolution depth model for the Great Barrier Reef and Coral Sea, Marine and Tropical Sciences Research Facility (MTSRF) Project 2.5i.1a Final Report, Reef and Rainforest Research Centre, Cairns, Australia, 13pp, 2010.

Book, J. W., Jones, N., Lowe, R., Ivey, G., Steinberg, C. R., Brinkman, R. M., Rice, A. E., Bluteau, C., Smith, S. R., Smith, T. A., and Matt, S.: Propagation of internal tides on the Northwest Australian Shelf studied with time-augmented empirical 495 orthogonal functions, in: Proceedings of the 20th Australasian Fluid Mechanics Conference, Perth, Australia, 5-8 December 2016, http://people.eng.unimelb.edu.au/imarusic/proceedings/20/744\%20Paper.pdf, 2016.

Codiga, D.L.: Unified tidal analysis and prediction using the UTide Matlab functions, Technical Report 2011-01, Graduate School of Oceanography, University of Rhode Island, Narragansett, RI, 59pp, ftp://www.po.gso.uri.edu/pub/downloads/codiga/pubs/2011Codiga-UTide-Report.pdf, 2011.

500 Egbert, G.D. and Erofeeva, S.Y.: Efficient inverse modelling of barotropic ocean tides, J. Atmos. Oceanic Technol., 19(2), 183-204, doi: 10.1175/1520-0426(2002)019<0183:EIMOBO>2.0.CO;2, 2002.

Engwirda, D.: JIGSAW(GEO) 1.0: locally-orthogonal staggered unstructured grid generation for general circulation modelling on the sphere, Geosci. Model Dev., 10 (6), 2117-2140, doi: 10.5194/gmd-10-2117-2017, 2017.

Griffin, D. A., Middleton, J. H. and Bode, L.: The tidal and longer period circulation of Capricornia, southern Great Barrier

Reef, Aust. J. Mar. Freshwater Res., 38, 461-474, 1987. 
https://doi.org/10.5194/os-2020-107

Preprint. Discussion started: 11 December 2020

Haigh, I. D., Wijeratne, E. M. S., MacPherson, L. R., Pattiaratchi, C. B., Mason, M. S., Crompton, R. P., and George, S.: Estimating present day extreme total water level exceedance probabilities around the coastline of Australia: tides, extra-tropical storm surges and mean sea level, Climate Dynamics, 42, 121-138, doi: 10.1007/s00382-012-1652-1, 2014.

Herzfeld, M.: An alternative coordinate system for solving finite difference ocean models, Ocean Modelling, 14 (3-4), 174196, doi: 10.1016/j.ocemod.2006.04.0022006, 2006.

Herzfeld, M., Engwirda, D., and Rizwi, F.: A coastal unstructured model using Voronoi meshes and C-grid staggering, Ocean Modelling, 148, doi: 10.1016/j.ocemod.2020.101599, 2020.

Herzfeld, Mike; Griffin, David; Hemer, Mark; Rosebrock, Uwe; Rizwi, Farhan; Trenham, Claire (2020): AusTEN National Tidal model data. v2. CSIRO. Data Collection. https://doi.org/10.25919/nqdc-1v40 .

515 Lyard, F. H., Allain, D. J., Cancet, M., Carrère, L., and Picot, N.: FES2014 global ocean tides atlas: design and performances, Ocean Sci. Discuss., doi: 10.5194/os-2020-96, in review, 2020.

Middleton, J.H., Buchwald V.T. and Huthnance, J.M.: The anomalous tides near Broad Sound, Continental Shelf Research 3 , 359-381, doi: 10.1016/0278-4343(84)90017-7, 1984.

Pawlowicz R., Beardsley, B. and Lentz, S.: Classical tidal harmonic analysis including error estimates in MATLAB using

T_TIDE, Computers and Geosciences 28, 929-937, doi: 10.1016/S0098-3004(02)00013-4, 2002.

Penesis, I., Hemer, M., Cossu, R., Nader, J. R., Marsh, P., Couzi, C., Hayward, J., Sayeef, S., Osman, P., Rosebrock, U., Grinham. A., Herzfeld, M. and Griffin, D.: Tidal Energy in Australia: Assessing Resource and Feasibility in Australia's Future Energy Mix, Australian Maritime College, University of Tasmania, 2020.

Ray, R. D., Egbert, G. D. and Erofeeva S. Y.: Tide predictions in shelf and coastal waters - status and prospects, in: Coastal

525 Altimetry, edited by: Vignudelli, S., Kostianoy, A. G., Cipollini, P. and Benveniste, J., Springer-Verlag, Berlin, Germany, 191-216, 2011.

Ringler, T. D., Thuburn, J., Klemp J. B. and Skamarock, W. C.: A unified approach to energy conservation and potential vorticity dynamics on arbitrarily structured C-grids, J. Comput. Phys., 229 (9), doi: 10.1016/j.jcp.2009.12.007, 2010.

Sahuc, E., Cancet, M., Fouchet, E., Lyard F., Dibarboure, G. and Picot, N.: Bathymetry Improvement and High Resolution

530 Tidal Modelling around Australia, Ocean Surface Topography Science Team meeting, October 20-23, 2020.

Seifi, F., Deng, X., Andersen, O. B.: Assessment of the accuracy of recent empirical and assimilated tidal models for the Great Barrier Reef, Australia, using satellite and coastal data, Remote Sens., 11, 1211, doi: 10.3390/rs11101211, 2019.

Stammer, D., Ray, R. D., Andersen, O. B., Arbic, B. K., Bosch, W., Carrère, L., Cheng, Y., Chinn, D. S., Dushaw, B. D., Egbert, G. D., Erofeeva, S. Y., Fok, H. S., Green, J. A. M., Griffiths, S., King, M. A., Lapin, V., Lemoine, F. G., Luthcke, S.

B., Lyard, F., Morison, J., Müller, M., Padman, L., Richman, J. G., Shriver, J. F., Shum, C. K., Taguchi, E. and Yi, Y.: Accuracy assessment of global barotropic ocean tide models, Rev. Geophys., 52, 243-282, doi:10.1002/2014RG000450, 2014. Thuburn, J., Ringler, T. D., Skamarock, W. C. and Klemp, J. B.: Numerical representation of geostrophic modes on arbitrarily structured C-grids, J. Comput. Phys., 228 (22), 8321-8335, doi: 10.1016/j.jcp.2009.08.006, 2009. 
https://doi.org/10.5194/os-2020-107

Preprint. Discussion started: 11 December 2020

(c) Author(s) 2020. CC BY 4.0 License.

(c) (i)

Timko, P. G., Arbic, B. K., Richman, J. G., Scott, R. B., Metzger, E. J. and Wallcraft, A. J.: Skill testing a three-dimensional

global tide model to historical current meter records, J. Geophys. Res.: Oceans, 118, 6914-6933, doi: 10.1002/2013JC009071, 2013.

Wijeratne, E. M. S., Pattiaratchi, C. B., Eliot, M. and Haigh, I. D.: Tidal characteristics in Bass Strait, south-east Australia, Estuarine, Coastal Shelf Sci., 114, 156-165, doi: 10.1016/j.ecss.2012.08.027, 2012.

\section{Figure Captions}

Figure 1 Model mesh spacing ( $\mathrm{km}, \log$ scale). Abbreviated names are: $\mathrm{CC}=\mathrm{Clarence}$ Channel, VanDG=Van Diemen Gulf, GOC $=$ Gulf of Carpentaria, CGBR=Central Great Barrier Reef, SGBR=Southern GBR, SEQ=Southeast Queensland, NSW=New South Wales, Bass=Bass Strait, Tas=Tasmania, Banks=Banks Strait, SA=South Australia, SW=South West......2 Figure 2 Model depth (m, log scale, spanning just a restricted range). Otherwise like Fig. 1.

550 Figure $3 \mathrm{M} 2$ height amplitude as a colour-fill map (the model) and points (observations), and inset as a quantity-quantity plot. Statistics listed are percentiles of 1) the whole model height field, 2) m=model at validation sites, 3) model error m-o and 4) $\mathrm{o}=$ observed values. $\langle|\mathrm{m}-\mathrm{o}|>$ is the Mean of the Absolute value of $\mathrm{m}-\mathrm{o} .\langle\mathrm{m}-\mathrm{o}\rangle$ is the mean error, or bias. $\langle\mathrm{m}\rangle$ and $\langle\mathrm{o}\rangle$ are the mean modelled and observed amplitudes. A log scale is used, starting at $10 \mathrm{~cm}$, so not all points can be shown....... 10

Figure 4 M2 height phase (otherwise like Fig. 3, except the y-axis of the inset is the phase error rather than phase).

555 Figure 5 Amplitude of the M2 major axis velocity, otherwise like Fig. 3. Black (model, at a random subset of grid points) and magenta (observed) velocity ellipses use the scale shown.

Figure 6 Amplitude of the M2 major axis velocity for Bass Strait, otherwise like Fig. 5, except that percentiles of the model at the locations of the observations are not listed. .20

Figure 7 Amplitude of the M2 major axis velocity for Banks Strait, otherwise like Fig. 5 .............................................2

560 Figure 8 Amplitude of the M2 major axis velocity for the Kimberley, otherwise like Fig. 5. .23

Figure 9 Amplitude of the M2 major axis velocity for the Darwin region, otherwise like Fig. 5 ........................................24

Figure 10 Amplitude of the M2 height for the Darwin region, otherwise like Fig. 3 .........................................................2 25

Figure 11 Amplitude of the M2 major axis velocity for the Southern Great Barrier Reef region, otherwise like Fig. 5 ......... 26

Figure 12 Amplitude of the M2 major axis velocity for the South Australia region, otherwise like Fig. 5............................28 